\title{
OPEN Biochemical characterisation of a collagenase from Bacillus cereus strain Q1
}

\begin{abstract}
Isabel J. Hoppe, Hans Brandstetter ${ }^{\bowtie}$ \& Esther Schönauer ${ }^{\bowtie}$
Collagen is the most abundant protein in higher animals and as such it is a valuable source of amino acids and carbon for saprophytic bacteria. Due to its unique amino acid composition and triple-helical tertiary structure it can however only be cleaved by specialized proteases like the collagenases secreted by some bacteria. Among the best described bacterial collagenases are ColG and ColH from Clostridium histolyticum. Many Bacillus species contain homologues of clostridial collagenases, which play a role in some infections caused by $B$. cereus. Detailed biochemical and enzymatic characterizations of bacillial collagenases are however lacking at this time. In an effort to close this gap in knowledge we expressed ColQ1 from B. cereus strain Q1 recombinantly, investigated its metal dependency and performed peptide, gelatin and collagen degradation assays. Our results show that ColQ1 is a true collagenase, cleaving natively folded collagen six times more efficiently than ColG while at the same time being a similarly effective peptidase as ColH. In both ColQ1 and ColG the ratelimiting step in collagenolysis is the unwinding of the triple-helix. The data suggest an orchestrated multi-domain mechanism for efficient helicase activity.
\end{abstract}

Collagen is the most abundant protein in mammalian bodies and makes up approximately $30 \%$ of the total protein content ${ }^{1}$. It is found in tendons, bone, cartilage, ligaments and skin, as an integral part of the extracellular matrix. There are numerous types of collagen, which all contain a characteristic right-handed triple helix composed of three left-handed $\alpha$-chains and type I-the most abundant form of collagen-is almost exclusively made up of this triple helix. The helical structure is supported by a glycine at every third amino acid position and a high content of proline and hydroxyproline ${ }^{1-3}$.

This unusual structure and the high content of imino acids give collagen a remarkable tensile strength and a high resistance to proteolysis ${ }^{4}$. Even endogenous collagenases like MMP-1 can only cleave native collagen at one single site ${ }^{5}$. In contrast to that, bacterial collagenases can cleave collagen at multiple sites and ultimately degrade it into small peptides ${ }^{6,7}$. The best-described bacterial collagenases are ColG and $\mathrm{H}$ from Clostridium histolyticum. They are large $(\approx 115 \mathrm{kDa})$ multi-domain proteins consisting of an $\mathrm{N}$-terminal collagenase unit (CU) which in turn is subdivided into the activator domain $(\mathrm{AD})$ and the peptidase domain $(\mathrm{PD})^{8,9}$. The collagenase unit is followed by a varying composition of accessory domains that are involved in substrate recognition and collagen swelling ${ }^{10,11}$.

The peptidase domain contains the catalytic zinc, coordinated by the two histidine residues in the HEXXH motif and a downstream glutamate characteristic for gluzincins ${ }^{12-14}$. It can be further divided into a catalytic and a helper subdomain. The catalytic subdomain is again comprised of an upper and a lower half-domain, with the catalytic zinc ion located at the interface of the two ${ }^{15,16}$.

The primary function of bacterial collagenases is the degradation of collagen as an amino acid and nitrogen source, and as such they enable the recycling of collagen within the global nitrogen cycle ${ }^{17,18}$. They are however also relevant as virulence factors in some diseases such as gas gangrene $(C \text {. perfringens })^{6}$ or botulism $(C$. botuli$n u m)^{6}$, and therefore present interesting targets for novel antibiotics ${ }^{19}$. Furthermore, collagenases isolated from $C$. histolyticum are in medical and biotechnological use as wound debridement agents ${ }^{20}$, treatment for Dupuytren's contracture $^{21,22}$, islet cell isolation ${ }^{23-25}$ and in the food and leather industry ${ }^{26,27}$.

In contrast to clostridial collagenases, there is only little known about collagenolytic enzymes from bacilli. It has been shown that, similarly to clostridia, bacilli can secrete collagenases into the culture medium ${ }^{28-30}$ and these can play a role in pathogenesis. Bacillus thuringiensis, a widely used bacterial insecticide, utilizes ColB for host invasion ${ }^{31}$ and it has been observed that collagenases play a role in B. cereus mediated endophthalmitis ${ }^{32}$ and periodontal disease ${ }^{33}$. However, to our knowledge there is no detailed enzymatic or structural data available 
on collagenases from bacilli. We found two putative collagenases (by homology to ColG from C. histolyticum) within the genome of the $B$. cereus strain Q1, reportedly an extremophilic organism ${ }^{34}$. In an effort to close the gap in knowledge about bacillial collagenases, we chose to recombinantly express and characterize one of them (UniProt accession B9J3S4), termed ColQ1 from here on.

\section{Results}

Bioinformatic analysis. Protein sequence alignment using ClustalOmega ${ }^{35}$ of ColQ1 with the clostridial collagenases ColG, $\mathrm{H}$ and T and ColA from B. cereus strain ATCC 14579 showed high sequence identities of approximately $45 \%$ to the clostridial collagenases and over $70 \%$ to the bacillus collagenase ColA. Consistent with previous studies ${ }^{16}$, the analysis with SignalP and conserved domains databases predicted the presence of (1) an N-terminal 30 amino acid signal sequence for extracellular secretion, (2) a propeptide (31-93) with unclear function, (3) an M9-like domain (94-366), which functions as an activator domain for collagenolysis (but as nuclear transport receptor in eukaryotes) $)^{16,36}$, (4) a peptidase M9 family domain (376-765; referred to as peptidase domain), (5) one polycystic kidney disease (PKD)-like domain (767-850) and (6) one collagen-binding domain (CBD, 853-965), Fig. 1a ${ }^{37-39}$. Domain-wise sequence alignments (Fig. 1b) showed that the similarities are clustered to the peptidase domain (PD) and that the similarity to the bacillial collagenase ColA is much higher than to the three clostridial collagenases (Fig. 1c). The catalytic HEXXH motif and the downstream glutamic acid as third zinc-binding residue that are characteristic for zinc-metalloproteases of the peptidase family M9 are conserved, as are the calcium-binding residues in the peptidase domain and accessory domains (Fig. 1b, indicated in orange and red respectively). The peptidase domain of clostridial collagenases can be further divided into a helper and a catalytic subdomain, with the latter being made up of an upper and a lower half-domain ${ }^{15}$. The boundaries between these subdomains are indicated by solid lines (catalytic and helper subdomains) and dashed lines (upper and lower catalytic half-domain) in Fig. 1a,b. For ColQ1 residues Y94-K965 therefore represent the mature, full-length enzyme, residues Y94-G765 the collagenase unit, Y94-N366 the activator domain (AD) and L376-G765 the peptidase domain (PD).

Recombinant expression and purification of ColQ1. Based on the production strategy for clostridial collagenases $^{40}$, the ColQ1 variants were recombinantly expressed in E. coli NiCo21(DE3) cells and purified by immobilized metal affinity chromatography (IMAC) using an $\mathrm{N}$-terminal $\mathrm{His}_{6}$-tag, followed by tag removal via tobacco etch virus (TEV) protease, rechromatography and size exclusion chromatography as a final polishing step.

All ColQ1 variants (Y94-K965: full-length mature FL, Y94-G765: CU, E502A dead mutant of both, Y94N366: AD, L376-G765: PD) were successfully overexpressed in E. coli NiCo21(DE3) cells in soluble form and purified by IMAC (Fig. 2a). After tag removal we continued with the fractions that contained cleaved protein (flow-through and wash) to size exclusion chromatography. A considerable amount of aggregated target protein and other contaminants was removed in this step (Fig. 2b). The final product was eluted at the expected retention time for its molecular weight and was estimated by SDS-PAGE to be at least $90 \%$ pure at a yield of 5-10 mg target protein per litre of cell culture.

Thermal stability of ColQ1 compared to the clostridial collagenases ColG and ColH. To verify the correct folding of recombinantly expressed ColQ1 and because B. cereus strain Q1 was reportedly isolated from the extreme conditions of a subsurface oil well ${ }^{34}$, i.e. high temperature and pressure, we compared the melting temperature $\left(\mathrm{T}_{\mathrm{m}}\right)$ to that of ColG and ColH (Fig. 3).

Figure 3a shows the melting curves of five different collagenase constructs: the comparison of the three collagenase units of $\mathrm{ColG}, \mathrm{ColH}$ and ColQ1 as well as the activator domain and peptidase domain of ColQ1. ColG $\mathrm{CU}$ exhibited a monophasic unfolding in all conditions, with melting temperatures of $41.5^{\circ} \mathrm{C}$ without addition or chelation of metal ions ("buffer" - yellow curve and bar), i.e. with potentially residual calcium and zinc bound from the purification and storage conditions. Upon addition of 10 and $100 \mathrm{mM}$ EDTA-a chelator of divalent metals - the melting temperature was lowered to 39.3 and $35.4^{\circ} \mathrm{C}$, respectively (light and dark orange curve/ bar). After addition of $10 \mathrm{mM} \mathrm{CaCl}_{2}$ and $10 \mu \mathrm{M} \mathrm{ZnCl}_{2}$ the $\mathrm{T}_{\mathrm{m}}$ rose by more than $10^{\circ} \mathrm{C}$ compared to the buffer control to $53.5^{\circ} \mathrm{C}$ (green curve/bar). This indicates that that the two domains of the ColG CU, the activator and the peptidase domains, exhibit similar thermal stabilities or unfold in concert.

Similar as ColG CU, ColH CU showed a monophasic melting behaviour in the HEPES-buffered saline ("buffer") and upon addition of $\mathrm{Ca}^{2+}$ and $\mathrm{Zn}^{2+}$, with very similar $\mathrm{T}_{\mathrm{m}} \mathrm{s}$ of $48.0^{\circ} \mathrm{C}$ and $49.2^{\circ} \mathrm{C}$, respectively. Upon addition of EDTA the melting behaviour became more complex, with a high starting signal followed by a melting point at $47.1^{\circ} \mathrm{C}(10 \mathrm{mM}$ EDTA $)$ or $46.8^{\circ} \mathrm{C}(100 \mathrm{mM}$ EDTA $)$. This indicates that under metal-chelating conditions one domain was unfolded from the beginning on and a second domain unfolded at higher temperature.

In stark contrast to ColG and ColH, ColQ1 CU gave a pronounced biphasic melting curve in the absence of additional metals or metal chelator. The first melting point could be only graphically estimated to approximately $30^{\circ} \mathrm{C}$, the inflection point (i.e. the melting temperature) of the second unfolding could be numerically fitted with a $\mathrm{T}_{\mathrm{m}}$ of $53.3^{\circ} \mathrm{C}$. This indicates that there were two domains or subdomains present that unfold independently from each other. Upon addition of EDTA this uncoupled two-step unfolding became even more pronounced with very high starting signals (reflecting molten globule-like state in one sub-domain) followed by a melting point at $53.4^{\circ} \mathrm{C}$ (orange line in Fig. 3a) and a melting point at approximately the same temperature for $100 \mathrm{mM}$ EDTA that is too shallow to perform an accurate Boltzmann fit. Remarkably, upon addition of $\mathrm{Ca}^{2+}$ and $\mathrm{Zn}^{2+}$ ColQ1 CU showed a monophasic unfolding with a $\mathrm{T}_{\mathrm{m}}$ of $56.8^{\circ} \mathrm{C}$, indicating not only a stabilizing effect but also a structural coupling of the folding domains. We hypothesised whether the biphasic unfolding of ColQ1 could be mapped to its activator domain and peptidase domain, cf. Fig. 1a. To test this hypothesis, we investigated the 
a

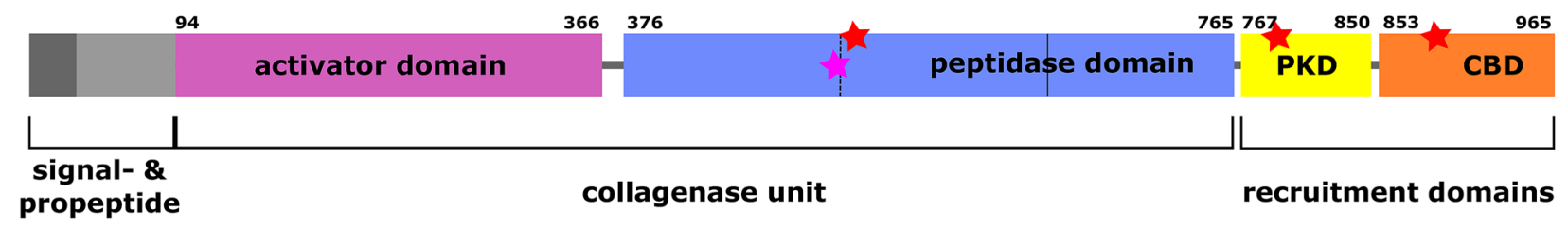

b

\section{collagenase unit}

ColQ1 $94-765$ ColA $93-764$ ColG 119-760 colT 57-731

Co1Q1 94-765 Co1A 93-764 ColA $119-760$ ColG 119-760 ColT $57-731$

Co1Q1 94-765 Co1A 93-764 COlH $41-721$ ColT $57-731$

ColQ1 94-765 ColA $93-764$ ColG 119-760 colf 41-721

ColQ1 94-765 ColA $93-764$ COIA $93-764$ ColH $41-721$ ColT 57-731

ColQ1 94-765 ColA $93-764$ ColG $119-760$ ColH $41-721$ ColT 57-731

\section{PKDs}

Co1Q1 767-850 ColA $768-849$ ColG 795-880 ColH $014-900$

Col01 767-850 ColA 768-849 ColG 795-880 ColH 725-810 ColH 814-900

\section{CBDs}

Co1Q1 853-965 ColA $852-960$ ColG 885-999 ColG 1004-1118 ColT 755-870
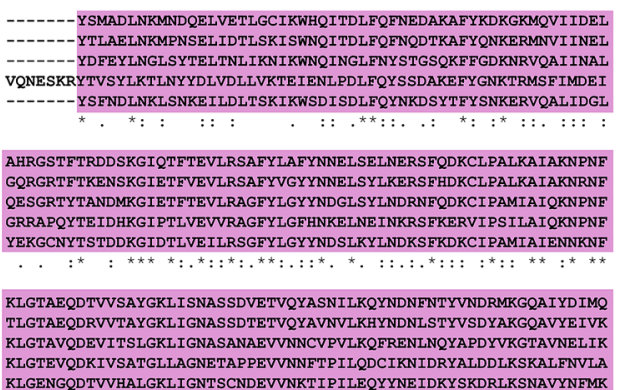
KLGTEVQDKIVSATGLLAGNETAPPEVVNNFTPILQDCIKNIDRYALDDLKSKALFNVL

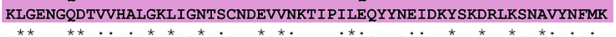
GIDYDIQSYLIEAR -KEANETMWYGKVDGF INE INRIALLNEVTPENKWLVNNGIYFASR GIDYDIQSYLQDTN -KQPNETMWYGKIDNF INEVNRIALVGNITNENSWLINNGIYYAGR

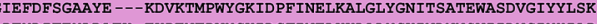
APTYDITEYLRATK -EKPENTPWYGKIDGFINELKKLALYGKINDNNSWIIDNGIYHIAP

YYDI

LGKFHSNPNKGLEVVTQAMHMYPRLSEPYFVAVEQITTNYNGKDYSGNTVDLEKIRKEGK VVVOMKTNYGGKDYSGNAVDLOKIREEGK FGLYSTNRNDIVOSL EKAVDMYK - YGKI AFVAMER T TWDYDGIGSNGKKVDHDKFIDDAE LGKLHSNNKIGIETLTEVMKVYPYLSMOHLOSADOIKRHYDSKDAEGNKI PLDKFKKEGK LSKYHSNPSIPHSVIDNCIEIFPDYSEQYFTAIEAIKEDFNSRDSKGNVIDINKLIEEGK

EQYLPKTYTFDDGSIVFKTGDKVSEEKIKRLYWAAKEVKAQYHRVIGNDKALEPGNADDI QQYLPKTYTFDDGSIVFKTGDKVTEEKIKRLYWAAKEVKAQYHRVIGNDKALEPGNADDV KHYLPKTYTFDNGTFIIRAGDKVSEEKIKRLYWASREVKSQFHRVVGNDKALEVGNADDV EKYCPKTYTFDDGKVI IKAGARVEEEKVKRLYWASKEVNSQFFRVYGIDKPLEEGNPDDI KHYLPKTYTFDNGKIIIKAGDKVEESKIQKLYWASKEVKSQFHRI IGNDKPLEVGNADDI ColA $93-764$ ColG 119-760 ColH $41-721$ ColT $57-731$

ColQ1 94-765 ColA $93-764$ ColG $119-760$ ColH $41-721$ ColT $57-731$

ColQ1 $94-765$ ColA 93-764 ColG $119-760$ ColH $41-721$ ColT $57-731$

Co101 $94-765$ ColA $93-764$ ColG $119-760$ ColH 41-721 ColT $57-731$

ColQ1 $94-765$ ColA $93-764$ ColG $119-760$ ColH $41-721$

Co101 $94-765$ ColA $93-764$ ColG $119-760$ ColH $41-721$ ColT $57-731$
ITIVIYNSPEEYQLNRQIYGYETNNGGIYI EETGTFFTYERTPEQSIYSLEELFR HEFTH ITIVIYNNPDEYQLNRQIYGYETNNGGIYI EEKGTFFTYERTPKQSIYSLEELFR HEFTH ITMKIFNSPEEYKFNININGVSTDNGGIYI EPRGTFYTYERTPQQSIFSLEELFR HEYT

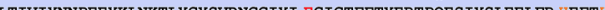
LTIVIYNNPEEYKLNKTIYGYSVDNGGIYI EGIGTFFTYERTPQESIYSLEELFR HEFT YIQGRYEVPGLFGRGDMYQ'-NERLTWFQ GNAEFFAGSTRTNNVVPRKSIISGISSDP YIOGRYEVPCLTGSGEMYO-NERITWFO GNAFTFASTRTMNVYPRKSMTSGISSDP YLQRYE VLAGE YLQGRYAVPGOWGRTKLYDL-NDRLTWYE GGAEIFAGSTRTSGIIPRKSIVSNIHNTTR YLQGRYL I PGLFNKGDFYKFNNGRITWEE GSAEFFAGSTRT - SVLPRKSMVGGLSKNP -

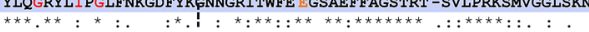

ASRYTAERTLFAKYG --SWDFYNYSFALQSYLYTHQFETFDKIQDLIRANDVKNYDAYRE ASRYTVKQILFSKYG --SWDFYKYSEALQSYLYNHQFETFDKLQDLIRANDVKNYDSYRE DHRYSLKKILNSGYDDSDWMFYNYGFAVAHYLYEKDMPTF IKMNKAILNTDVKSYDEIIK NNRYKLSDTVHSKYGA -SFEFYNYACMFMDYMYNKDMGILNKLNDLAKNNDVDGYDNYIR KERENADKLIHSKYSD - GWDFYKYGYAFSDYMYNNNKKLFSDLVSTMKNNDVKGYEALIE

CYO" SLSNNTOINAEYOA YMOOL IDNODK YNVPKVINDYLIOHAPKPLAEVKNEIVDVANIKDA SLSNNTQLNAEYQAYMQQLIDNQDK NVPKVINDYLIQHAPKPLAEVKNEIVDVANIKDA DTS

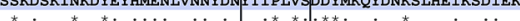

KMTKHSSQFFNTFTLEGTYTGSVTKGESEDWNAMSKKVNEVLLELLAQKEWSGYKTVTAYF SVTAFKSOYFNTFTI RGTYTGETSKGEFRDNDFMSKKIDGTIEST.AKNSWSGYKTITAY KSEVKKSOYFSTFTLRGSYTGGASKGKLEDQKAMNKFIDDSIKKLDTYSWSGYKTLTAYF QITKESSQYFDTYNLKATYTLSSNKGE ISNWNYMNNNKINEALNKLDNLSWGGYKTVTAYF

VNYRUNSSNEFEYDVVFHGIAKDDG VNYRVNAANQFEYDIVFHGVATEEK TNYRVTSDNKVQYDVVFHGVITDNA TNYKVDSSNRVTYDVVFHGYLPNEG SNPRLNSNNEVYYDIVFHGLISHNK
NK APTVNINGPYNGLVKEGIQFKSDGSK DED GKIVSYLWDFGDGRT -STEVNPVHVYERE KT TTIVNMNGPYSGIVNEEIQFHSDGTK SEN GKVISYLWNFGDGTT - STEANPTHVYGEK

NK APIAKVTGPSTGAVGRNIEFSGKDSK DED GKIVSYDWDFGDGAT -SRGKNSVHAYKKA

NS IPYGYIG

$\therefore \quad: *^{*} .: *^{*} \ldots:$ : : *.: .**:********

GSYKVALIVK D DKGKESKSETTVTV -

GTYTVELTVK D SRGKESKEQTKVTV -

GTYNVTLKVT D DKGATATESFTIEIKM

GTYTVKLKVT D DKGESSVSTTTAEIKD.

GEYTVTLRVM D SSGQMSERTMRIKITD

-GSLT ESEPNN RPEEANRI -GLNTTIKGSLIGG DHTD VYTFNVASAKDIDISVLNEY --G ----- DPQTSE SYEEEKVI-PENTLVKGNLITP DQTD VYTFNVTDPKEVDISVVNEQ --N TPITK EMEPND DIKEANGPIVEGVTVKGDINGS DDAD TFYFDVKEDGDVTIEIPYSG --S YPIGT EKM N

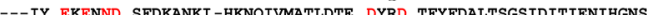
IKKIH
C

\begin{tabular}{|l|c|c|c|c|c|c|}
\hline & AD & PD & PKD1 & PKD2 & CBD1 & CBD2 \\
\hline ColA & 85 & 92 & 81 & - & 77 & - \\
\hline ColG & 65 & 71 & 59 & - & 48 & 59 \\
\hline ColH & 63 & 73 & 65 & 56 & 59 & - \\
\hline ColT & 64 & 77 & - & - & 54 & 62 \\
\hline ColQ1 & 100 & 100 & 100 & - & 100 & - \\
\hline
\end{tabular}

Figure 1. Bioinformatic analysis of ColQ1 (a) Schematic domain architecture of ColQ1 based on sequence homology to microbial collagenases and conserved domain predictions ${ }^{54,55}$. Pink star indicates the zinc-binding site and red stars indicate the conserved calcium-binding sites. (b) Multiple alignment of mature sequences of ColQ1 (B9J3S4) from B. cereus strain Q1, ColA (Q81BJ6) from B. cereus strain ATCC 14579, ColG (Q9X721) and ColH (Q46085) from C. histolyticum and ColT (Q899Y1) from C. tetani. Magenta, light blue, orange and red are the activator domain, peptidase domain, zinc-binding residues and calcium-binding residues ${ }^{73,74}$, respectively. Division of the peptidase domain into the catalytic and the helper subdomain is indicated by solid lines. Division of the catalytic domain into the upper and lower half-domain is indicated by a dotted line in (a) and (b). The alignment was aided by Clustal Omega ${ }^{75}$. (c) Similarity [\%] of the activator (AD), peptidase (PD), polycystic kidney disease like (PKD) and collagen-binding domains (CBD) of ColA, G, H and T to the corresponding domains in ColQ1. Darker blue indicates higher similarity. Calculated by BLASTp ${ }^{56}$. 
a

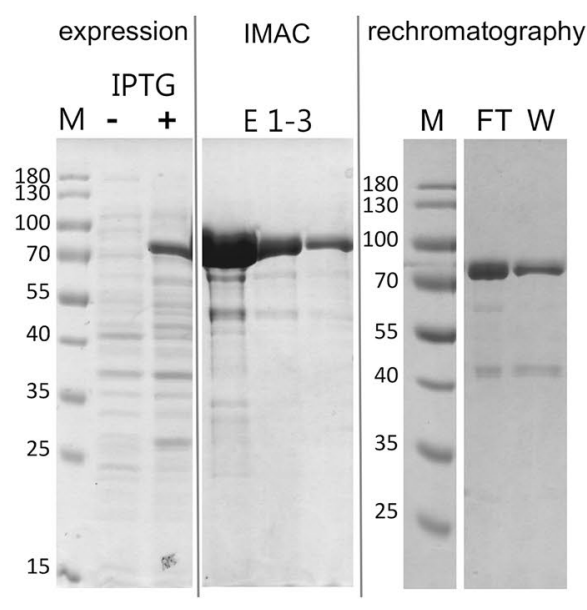

b

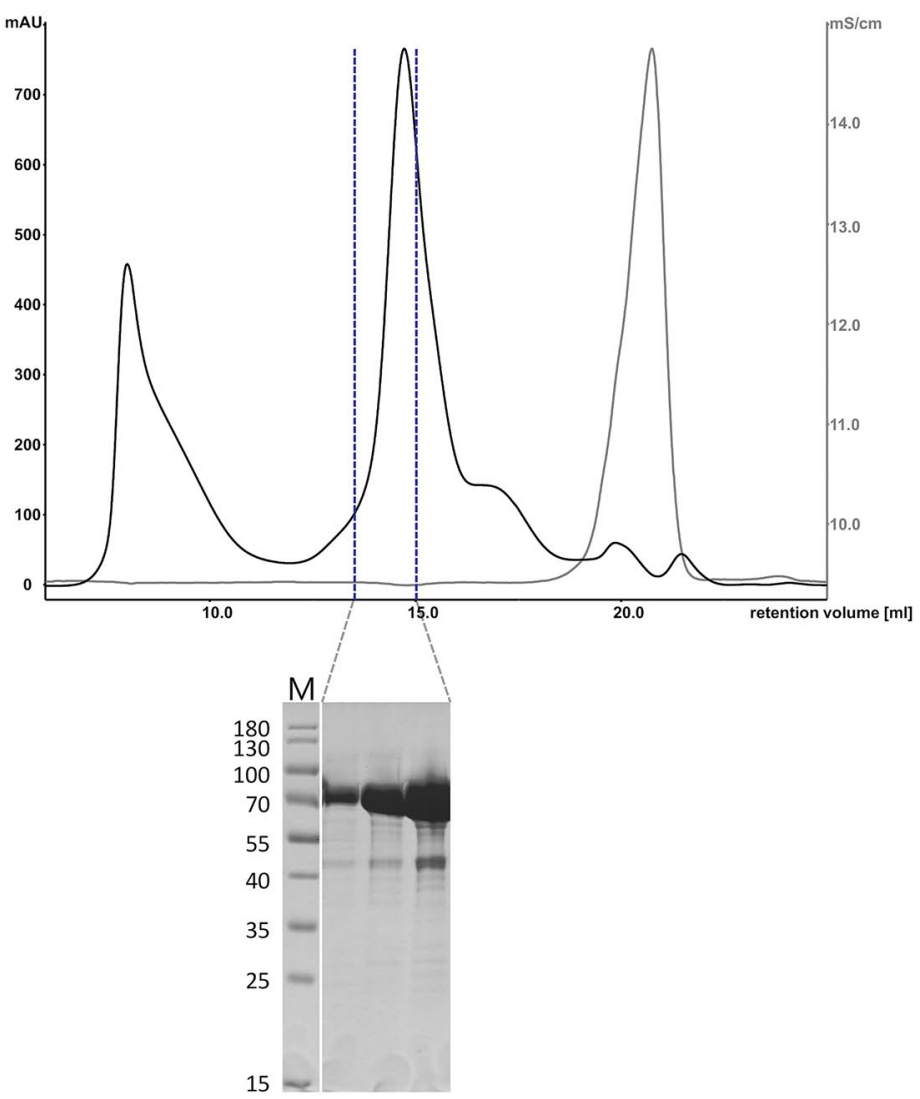

Figure 2. Representative purification of ColQ1 CU (a) Expression, IMAC and removal of $\mathrm{His}_{6}$-tag. M: molecular weight standards, IPTG $\mp$ : total cell lysate before induction and at time of harvest, E1-3: elution with $250 \mathrm{mM}$ imidazole, rechromatography FT (flow-through) and W (wash): fractions containing target protein after $\mathrm{His}_{6}$-tag cleavage by TEV-protease. (b) Size exclusion chromatography and SDS-PAGE of pure protein fractions. The blue dotted lines indicate the fractions that were analysed in the depicted SDS-PAGE gel and subsequently pooled for further use. M: molecular weight standards.

thermal stability of the individual AD and PD domains. ColQ1 AD did not show this metal dependent biphasic unfolding, but instead gave a monophasic melting curve in each condition with a $\mathrm{T}_{\mathrm{m}}$ of $48.2^{\circ} \mathrm{C}$ in the buffer saline and with addition of 10 and $100 \mathrm{mM}$ EDTA. The addition of $\mathrm{Ca}^{2+}$ and $\mathrm{Zn}^{2+}$ lowered the $\mathrm{T}_{\mathrm{m}}$ by approximately $4{ }^{\circ} \mathrm{C}$ to $43.9^{\circ} \mathrm{C}$. Importantly, however, ColQ1 PD exhibited a biphasic unfolding in all buffer conditions, which was particularly pronounced in the control buffer and when EDTA was present. In the buffer condition the melting temperatures were 34.5 and $48.9^{\circ} \mathrm{C}$ for the observed two sequential unfolding events. With addition of 10 and $100 \mathrm{mM}$ EDTA the curves showed high initial fluorescence, indicating that the first (sub-)domain was unfolded from the beginning on. With $10 \mathrm{mM}$ EDTA present the second $\mathrm{T}_{\mathrm{m}}$ could still be determined to be $49.3^{\circ} \mathrm{C}$. However in the presence of $100 \mathrm{mM}$ EDTA, the transition became too shallow for an inflection point to be determined numerically. With both $\mathrm{Ca}^{2+}$ and $\mathrm{Zn}^{2+}$ present, the first unfolding event in the biphasic profile almost vanished. Its melting point could only be graphically estimated to approximately $49^{\circ} \mathrm{C}$, while the second dominant transition exhibited a $\mathrm{T}_{\mathrm{m}}$ of $56.8^{\circ} \mathrm{C}$. The thermal unfolding of the ColQ1 peptidase domain thus qualitatively and quantitatively resembles the bimodal unfolding of the ColQ1 collagenase unit.

Under ideal conditions (i.e. with $\mathrm{Ca}^{2+}$ and $\mathrm{Zn}^{2+}$ supplied in the buffer), ColQ1 CU therefore had the highest $\mathrm{T}_{\mathrm{m}}$ out of these three collagenases, but it also exhibited the strongest dependence on metals for stability.

Enzymatic activity. To test whether this novel protein has collagenase-like enzymatic activity, we assayed the peptidase activity using the collagen-like peptidic substrate N-[3-(2-Furyl)acryloyl]-Leu-Gly-ProAla (FALGPA) (Fig. 4a). As reported previously, among the clostridial collagenases ColH has the highest activity towards this substrate while ColG has the lowest turnover ${ }^{41}$. The putative bacillial collagenase ColQ1 indeed showed activity towards FALGPA with approximately $60 \%$ of the reaction velocity of ColH and over 100 -fold higher velocity than ColG.

To put the computational annotation as zinc-metallopeptidase to the test, we measured the activity of ColQ1 (CU and FL) towards the relatively simple substrate gelatin in the presence of different inhibitors (Fig. $4 \mathrm{~b}$ ). We tested E-64 and PMSF, broad-spectrum cysteine and serine protease inhibitors, respectively. Both inhibitors did not inhibit ColQ1. It is therefore highly unlikely that this enzyme is either a cysteine or a serine protease. 
a
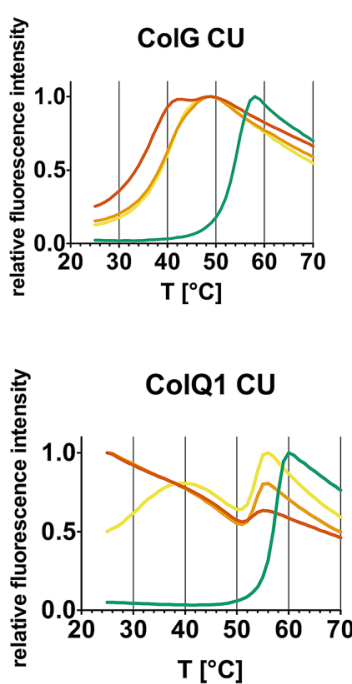

ColH CU

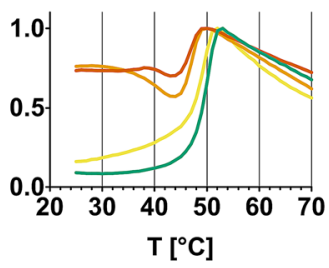

ColQ1 AD

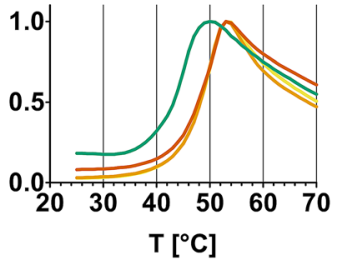

- buffer

- 10 mMEDTA

100 mMEDTA

$10 \mu \mathrm{MZnCl}$, $10 \mathrm{mM} \mathrm{CaCl}_{2}$

b

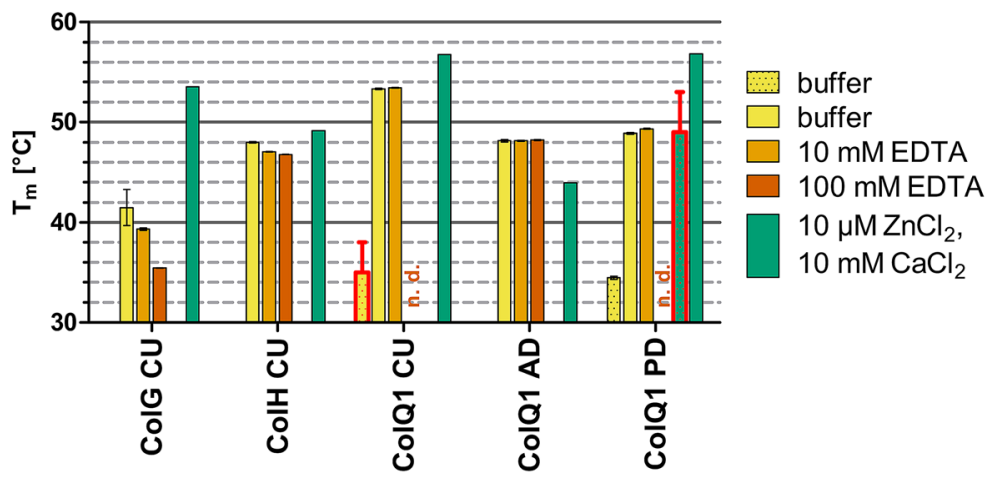

Figure 3. Differential scanning fluorimetry (DSF) of collagenase units of ColG, ColH and ColQ1 and activator and peptidase domains of ColQ1. (a) Representative melting curves in $20 \mathrm{mM}$ HEPES, $80 \mathrm{mM} \mathrm{NaCl}, \mathrm{pH} 7.5$, $5 \times$ SYPRO orange dye without further additives (yellow), with $10 \mathrm{mM}$ EDTA added (orange), with $100 \mathrm{mM}$ EDTA added (dark orange) and with $10 \mu \mathrm{M} \mathrm{ZnCl}_{2}$ and $10 \mathrm{mM} \mathrm{CaCl}_{2}$ added (green). (b) Melting temperatures determined from the DSF curves by Boltzmann fitting. n. d.: no melting temperature determination possible. In case of ColQ1 CU \& PD the dotted and unfilled buffer bars are the two distinct first melting temperatures seen in (a). The melting temperatures that could not be determined numerically, but only graphically, are highlighted by bold red borders. Data are shown as mean $\pm S D(n=3)$.

EDTA, which also was detrimental to correct folding, and the more zinc-specific chelator 1,10-phenanthroline ${ }^{42}$ strongly inhibited the reaction.

These results show that ColQ1 is indeed an active metallopeptidase with a substrate preference for collagentypical sequences. Consequently, we wanted to characterize the activity more comprehensively, especially in comparison to the well-characterised clostridial collagenases. Figure 5 shows different experiments exploring ColQ1's gelatinolytic activity. A representative gelatin zymogram with ColQ1 FL and CU is shown in Fig. 5a. Clear bands on the Coomassie-stained SDS-PAGE gel indicate that the enzyme cleaved the gelatin copolymerized into the gel. Consistent with its metal dependence, ColQ1 FL and CU activities were reduced by EDTA and increased by the addition of $\mathrm{CaCl}_{2}$ in the developing buffer. The gelatinolytic activities clearly peaked at monomeric bands, but were also visible at higher molecular weight, suggesting a partially retarded migration of ColQ1 FL through the gelatin-containing SDS gel. Figure 5b compares the activity of ColQ1 CU towards fluorescein-labelled gelatin with that of ColG CU and $\mathrm{ColH} \mathrm{CU}$ at one given substrate concentration. ColQ1 CU had approximately one third of the activity of ColG CU and 60 times more activity than ColH CU. Since the gelatinolytic activity was in a similar range as that of ColG CU we compared these two enzymes more comprehensively using Michaelis-Menten kinetics. To ensure the physiological relevance of the results, we used gelatin derived from unlabelled type I collagen from rat tail as the substrate. Initial velocities were determined using a 
a

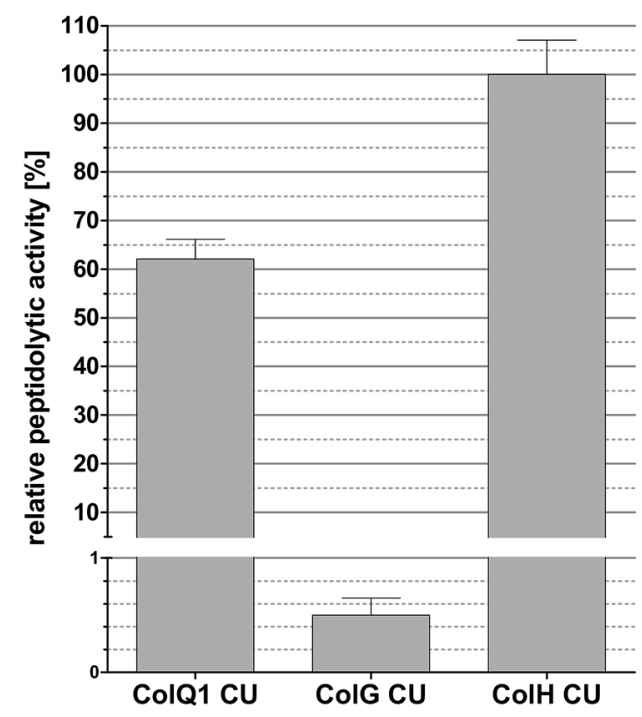

b

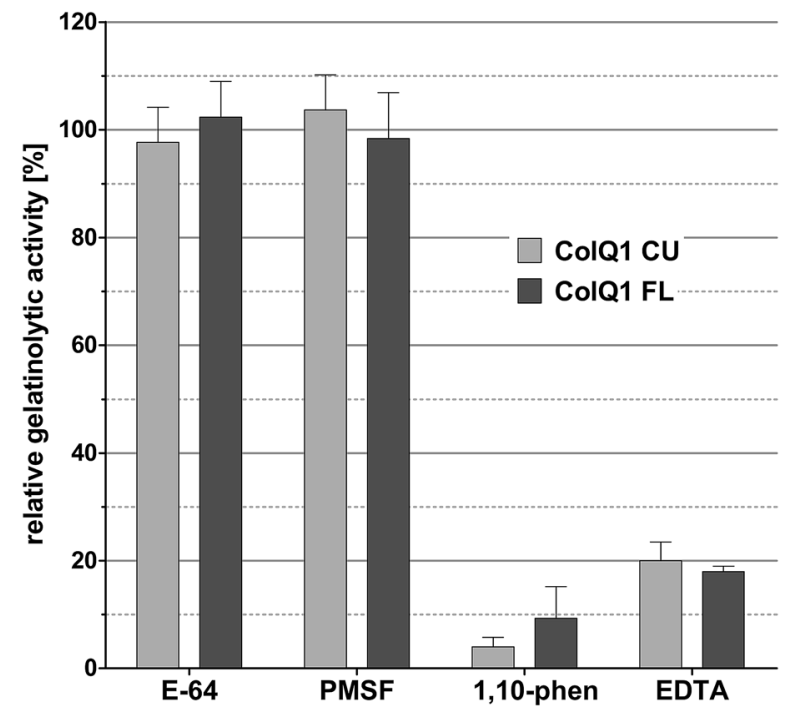

Figure 4. Initial enzymatic characterization of ColQ1. (a) Relative peptidolytic activities of ColQ1 CU, ColG $\mathrm{CU}$ and ColH CU against the collagenase-specific peptide substrate FALGPA. Data shows mean $\pm \mathrm{SD}(\mathrm{ColH}$ CU: $n=3$, ColG CU/ColQ1 CU: n=5). (b) Relative activities of ColQ1 FL and CU against fluorescein-labelled gelatin (DQ gelatin, Molecular Probes) after incubation with cysteine- and serine protease inhibitors E-64 and PMSF and metalloprotease inhibitors 1,10-phenanthroline and EDTA. Data are graphed as mean \pm SD $(n=3)$.

a
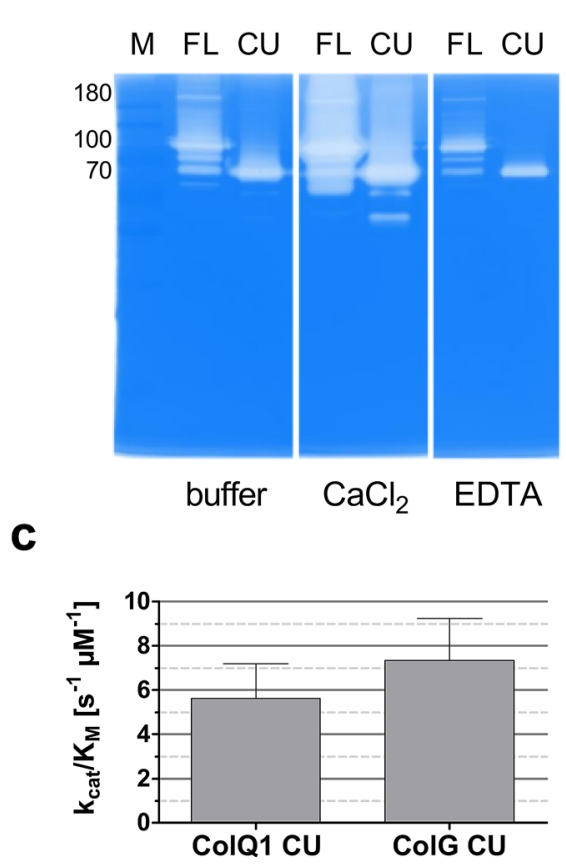

b

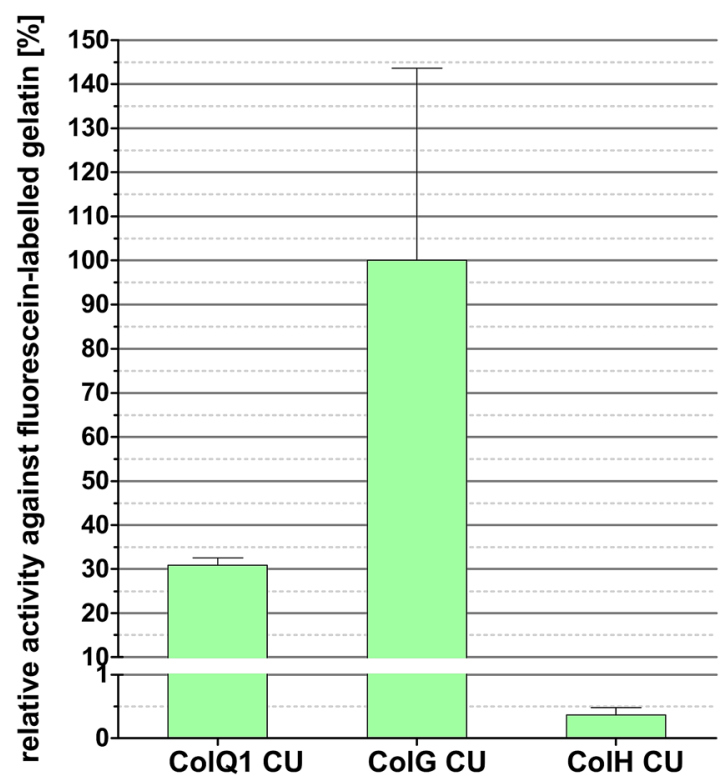

Figure 5. Activity of bacterial collagenases against gelatin (a) Zymogram showing the gelatinolytic activity of ColQ1 FL and CU in developing buffer without additives, with $5 \mathrm{mM}$ EDTA and with $5 \mathrm{mM} \mathrm{CaCl}_{2}$ added. Clear regions against blue background indicate gelatin in the gel has been cleaved. (b) Activity of the collagenase units of ColG, H and Q1 against fluorescein-labelled gelatin (DQ gelatin, Molecular Probes). (c) Catalytic efficiency $\left(\mathrm{k}_{\mathrm{cat}} / \mathrm{K}_{\mathrm{M}}\right)$ of ColG CU and ColQ1 CU towards gelatin from rat tail determined by discontinuous degradation assay using fluorescamine detection of neo-N-termini. Error bars indicate standard error of nonlinear Michaelis-Menten fit.

discontinuous cleavage assay where the substrate was mixed with enzyme, samples were taken at set time points 
a

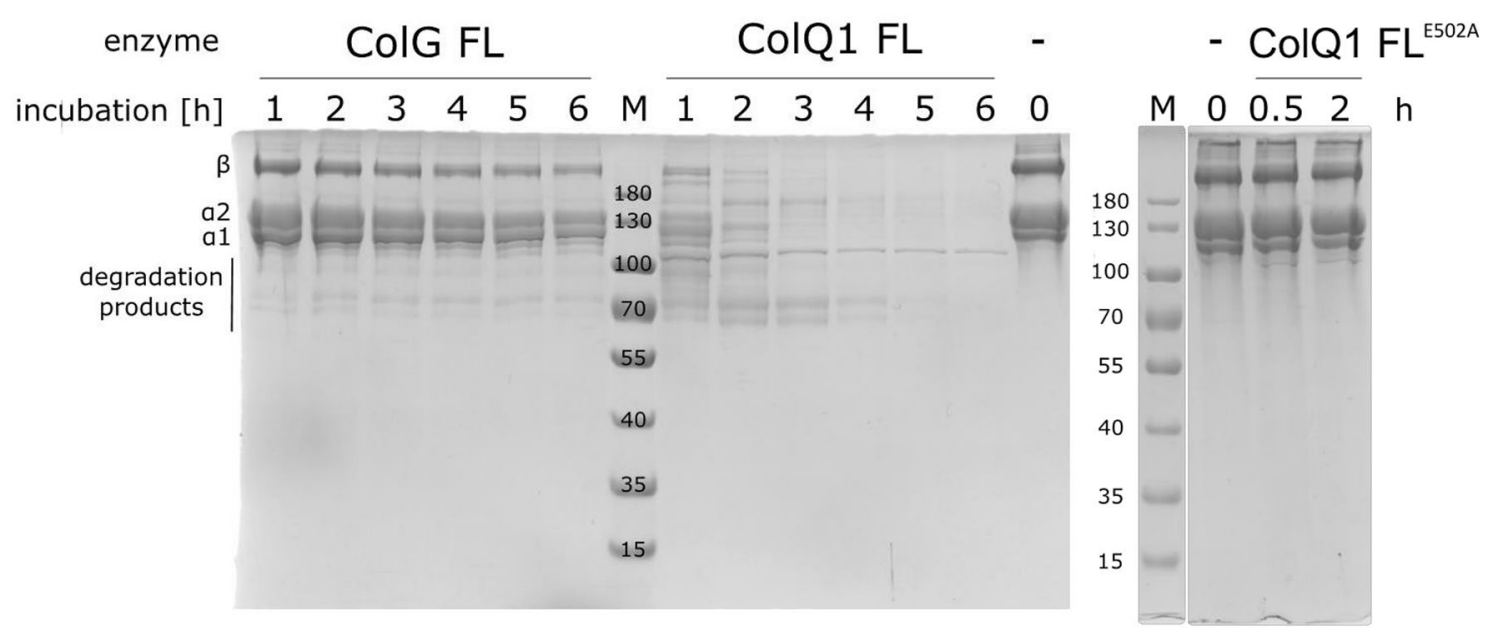

b

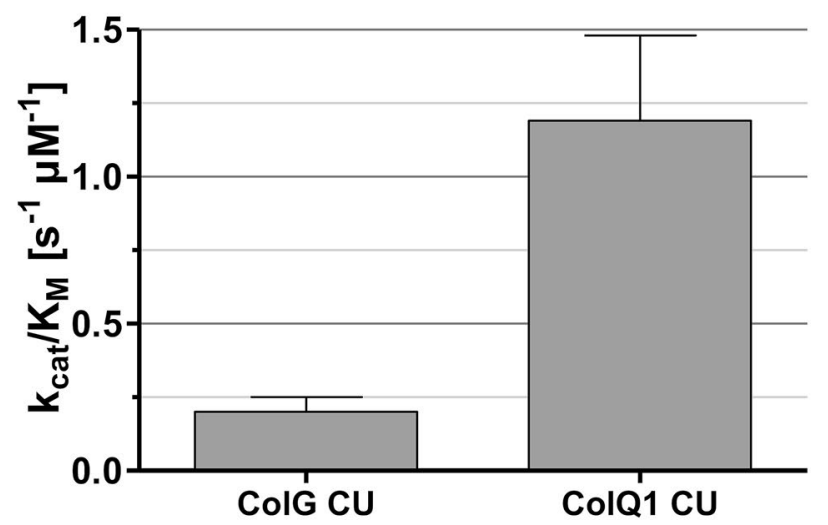

Figure 6. Activity of bacterial collagenases against collagen. (a) Collagenolytic activity of ColG and ColQ1 visualized on SDS-PAGE. M: molecular weight standards, ColG FL, ColQ1 FL and ColQ1 FL E502A (catalytic dead mutant) were incubated with $1 \mathrm{mg} / \mathrm{ml}$ type I collagen for the indicated times, $0: 1 \mathrm{mg} / \mathrm{ml}$ type I collagen without any protease. (b) Catalytic efficiency $\left(\mathrm{k}_{\mathrm{cat}} / \mathrm{K}_{\mathrm{M}}\right)$ of ColG CU and ColQ1 CU towards type I collagen from rat tail determined by discontinuous degradation assay using fluorescamine detection of neo-N-termini. Error bars indicate standard error of nonlinear Michaelis-Menten fit.

and the reaction was stopped by addition of EDTA. The progress was then quantified by reaction of primary amines with fluorescamine, which can be detected by fluorescence. After subtraction of the signal for uncleaved collagen this gives an accurate quantification of neo-N-termini generated by enzymatic cleavage (Fig. 5c). ColG $\mathrm{CU}$ and ColQ1 CU displayed similar kinetics of native gelatin degradation. Both enzymes exhibited a virtually identical affinity towards gelatin with a $\mathrm{K}_{\mathrm{M}}$ of approximately $1.4 \mu \mathrm{M}$ (ColG CU: $1.35 \pm 0.3 \mu \mathrm{M}$; ColQ1 CU: $1.36 \pm 0.3 \mu \mathrm{M})$ and $\mathrm{k}_{\mathrm{cat}}$ values of $9.9 \pm 0.7$ and $7.7 \pm 0.5 \mathrm{~s}^{-1}$, respectively. Accordingly, the gelatin turnover $\left(\mathrm{k}_{\mathrm{cat}} / \mathrm{K}_{\mathrm{M}}\right)$ was slightly lower for ColQ1 CU than for ColG CU (ColG CU: $7.3 \pm 1.9 \mathrm{~s}^{-1} \mu \mathrm{M}^{-1}$; ColQ1 CU: $5.6 \pm 1.6 \mathrm{~s}^{-1} \mu \mathrm{M}^{-1}$ ).

From these data (Figs. 4, 5) we conclude that ColQ1, annotated as a member of the gluzincin family M9 and a sequence homologue of the clostridial collagenases ColG, H and T, is indeed a calcium-dependent zincmetalloprotease with specificity for collagen-derived peptide sequences.

The hallmark of a true collagenase is the ability to cleave natively folded triple-helical collagen under physiological conditions ${ }^{43}$. We therefore incubated ColQ1 FL and ColG FL with bovine type I collagen for up to $6 \mathrm{~h}$ at $25^{\circ} \mathrm{C}$. Type I (atelo-) collagen comprises exclusively triple-helical content and in its native conformation it cannot be processed by most proteases. ColG FL cleaved approximately half of the collagen in the reaction mixture within $6 \mathrm{~h}$. In contrast, ColQ1 FL degraded the majority of the collagen already after one hour and after $5 \mathrm{~h}$ there was nearly no collagen visible in the Coomassie-stained SDS-PAGE (Fig. 6a). We can therefore conclude that ColQ1 is a true collagenase. In fact, it processes collagen much faster than ColG. As a control, we incubated collagen with a ColQ1 FL mutant in which the conserved glutamate of the HEXXH-motif characteristic for zinc-metalloproteases was changed to alanine (ColQ1 FL ${ }^{\mathrm{E} 502 \mathrm{~A}}$ ). By homology, this glutamate serves as the general acid/base in catalysis ${ }^{15,16}$. This mutant was not able to cleave collagen (Fig. 6a), further validating the annotation as a zinc-metalloprotease. 
To avoid the intricacies of quantifying collagen-derived product degradation assays monitored by SDS-PAGE, we further investigated the kinetics of collagen degradation in the same discontinuous assay as described for gelatin (Fig. 6b). We used the same type I collagen from rat tail; the substrates used in the gelatinolytic and collagenolytic assays therefore shared the same primary sequence. Collagen was used in its natively folded form while gelatin was prepared by collagen denaturation.

Using native collagen as a substrate, both enzymes exhibited substantially lower turnover rates than for gelatin, with catalytic efficiencies $\left(\mathrm{k}_{\mathrm{cat}} / \mathrm{K}_{\mathrm{M}}\right)$ of $0.2 \pm 0.05$ (ColG CU) and $1.19 \pm 0.29$ (ColQ1 CU) $\mathrm{s}^{-1} \mu \mathrm{M}^{-1}$ for collagen, as could be expected ${ }^{12}$. The only difference between the substrates gelatin and collagen is the triple-helical fold. Assuming a two-step processing of collagen, this comparison implies that the rate-limiting step in collagenolysis for these enzymes must be related to the unwinding of the triple helix.

With a $\mathrm{K}_{\mathrm{M}}$ of $1.72 \pm 0.4 \mu \mathrm{M}$ and a $\mathrm{k}_{\mathrm{cat}}$ of $2.1 \pm 0.13 \mathrm{~s}^{-1}$, ColQ1 CU displayed a two-fold higher affinity towards collagen than ColG CU and a three-fold higher turnover rate $\left(\mathrm{ColG} \mathrm{K}_{\mathrm{M}}: 3.40 \pm 0.7 \mu \mathrm{M}\right.$; $\left.\mathrm{ColG} \mathrm{k}_{\mathrm{cat}}: 0.70 \pm 0.05 \mathrm{~s}^{-1}\right)$. In effect, we found that ColQ1 CU can process folded collagen 6 times more efficiently than ColG CU.

\section{Discussion}

We have shown here that the general strategy for the high-yield expression and purification of clostridial collagenases in E. coli presented by Ducka et al. ${ }^{40}$ is also applicable to homologous collagenases from bacilli with only minor modifications. This approach yields mg-amounts of highly pure and monodisperse protein suitable for biochemical and enzymatic characterization.

As a first step towards a more comprehensive characterization of non-clostridial bacterial collagenases we have shown here-by the use of specific inhibitors and through mutation of the conserved zinc-orienting glutamate residue in the HEXXH-motif-that this novel enzyme from B. cereus strain Q1 is indeed a metalloprotease of the gluzincin class, as the bioinformatic annotation suggests. Its activity against triple-helical type I collagen under physiological buffer conditions shows that this enzyme is a true collagenase ${ }^{43}$.

In fact, ColQ1 is much more active against triple-helical collagen than ColG, the clostridial collagenase with the highest reported collagenolytic activity ${ }^{12}$. This is consistent with our recent report on the activity of ColA from B. cereus type strain ATCC $14579^{28}$ and indicates that, although historically less studied and therefore much less well described, bacillial collagenases may in general be much more efficient collagenolytic enzymes than clostridial collagenases. By determination of the kinetics towards collagen and its thermally denatured variant gelatin we showed that this difference can be explained by a higher helicase activity of ColQ1. The molecular mechanism for this high helicase activity cannot be fully explained by the data available at present and will have to be investigated further.

The to our knowledge only other comprehensive kinetic characterization of collagenolysis by ColG (termed $\beta$-collagenase in older publications) was conducted by Mallya et al. ${ }^{44}$ and determined a $\mathrm{K}_{\mathrm{M}}$ of $12 \mu \mathrm{M}$ and a $\mathrm{k}_{\text {cat }}$ of $1000 \mathrm{~h}^{-1}\left(\approx 0.28 \mathrm{~s}^{-1}\right)$ towards soluble type I collagen from rat tail at $25^{\circ} \mathrm{C}$. These results, while not identical, are in a similar range as the results presented in this study. Although the substrate used here is very similar (acetylated, soluble type I collagen from rat tails in a neutral buffer) there are some significant differences that can account for the slightly different results. Firstly, the enzyme was prepared in a very different manner. While we expressed the collagenases recombinantly in E. coli, in the previous study it was isolated from commercial C. histolyticum collagenase preparation by a series of chromatographic steps. Secondly, previous enzymatic reactions were carried out in $50 \mathrm{mM}$ Tricine, $200 \mathrm{mM} \mathrm{NaCl}, 10 \mathrm{mM} \mathrm{CaCl}_{2}, \mathrm{pH} 7.5$ and we now know that (1) both calcium and zinc are essential for correct folding and activity of clostridial collagenases and (2) tricine can act as a chelator of divalent metal ions ${ }^{45}$ and could therefore have influenced the activity, unlike the HEPES buffer used in the present study. Furthermore, in the previous study precipitation with $50 \%$ dioxane was used to remove uncleaved substrate. This was not necessary in our experimental design. Taking these experimental differences into account, the kinetic data determined here match the available literature reasonably well.

Clostridial collagenases are traditionally divided into class I collagenases with high collagenolytic activity $(\mathrm{ColG})$ and class II collagenases with high peptidolytic activity $(\mathrm{ColH})^{12}$. Its high collagenolytic and gelatinolytic activity would make ColQ1 a class I collagenase. However, ColQ1 also shows remarkably high peptidolytic activity, comparable to that of class II collagenase $\mathrm{ColH}$. This raises the question whether this division into collagenolytic class I and peptidolytic class II collagenases is applicable to non-clostridial collagenases. A possible explanation for the high peptidolytic activity of ColQ1 can be found in a comparison of the catalytic centres of clostridial and bacillial collagenases (Fig. 7) based on the crystal structures of ColH PD and ColG CU and a homology model of ColQ1 PD. As reported previously ${ }^{15}$, ColH has an additional zinc-coordinating residue (aspartate 421) in the upper catalytic half-domain, shortly before the substrate-binding edge strand, in a position where the other clostridial collagenases have a serine. This helps ColH to maintain a more rigid and stable catalytic centre, even in the absence of a complex substrate like gelatin or collagen to stabilize it. By contrast, ColG's active site has a low affinity to the catalytic zinc, accompanied by relatively high local flexibility ${ }^{15}$. ColQ1 and many other closely related putative collagenases have a glutamate in the position equivalent to Asp421 in ColH (Fig. 7, highlighted in pink), like aspartate a negatively charged amino acid side chain that could be expected to similarly stabilize the catalytic $\mathrm{Zn}^{2+}$ ion. Although this glutamate is located too far away from the catalytic zinc to interact with it in a homology model (Fig. 7b), it is conceivable that the loop region that contains it is flexible enough to change its position depending on the substrate that is bound. This loop could then "flip up" in order to enable collagen binding or "flip down" into a position resembling the catalytic centre of ColH to facilitate efficient peptidolytic activity. A conformational change like this could in part explain how Bacillus collagenases manage to straddle this dual high activity against peptidic and more complex substrates. Furthermore, the amino acid sequence of the selectivity filter-a loop region located approximately 50 amino acids downstream of the gluzincin-helix, forming a sort of lower lip in the catalytic centre ${ }^{15}$-resembles that of ColH more closely 
a

\section{ColG}

$\mathrm{ColH}$

ColQ1

B9ITQ0 B. cereus (strain Q1)

081BJ6 B. cereus (ATCC 14579)

A0A1J9V4Z8 $B$. anthracis

A0A109G8R9 B. mycoides

A0A1E4R6K6 L. fusiformis

A0A410MLN5 L. sphaericus

A0A1G6HLB3 B. Ionarensis

b

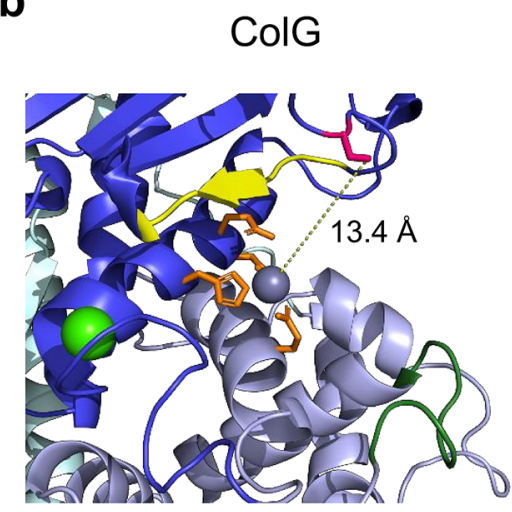

edge

central helix

485 INGV S TDN GGLYIE PRGTFYTYERTPQQSIFSLEELFR HEYTH YLQARYLVDGLWGQGPF 544 417 LYGY D TNN GGMYIE PEGTFFTYEREAQESTYTLEELFR HEYTH YLQGRYAVPGQWGRTKL 476 463 LYGY E TNN GGIYIE ETGTFFTYERTPEQSIYSLEELFR HEFTH YLQGRYEVPGLFGRGDM 522 466 LYGY E TNN GGLYIE GTGTFFTYERTPEESIYSLEELFR HEFTH YLQGRYEVPGLWGOGKM 525 462 LYGY E TNN GGIYIE EKGTFFTYERTPKQSIYSLEELFR HEFTH YLOGRYEVPGLFGSGEM 521 463 LYGY E TNN GGIYIE ETGTFFTYERTPEQSIYSLEELFR HEFTH YLQGRYEVPGLFGRGDM 522 463 LYGY E TNN GGIYIE ETGTFFTYERTPEQSIYSLEELFR HEFTH YLQGRYEVPGLFGRGDM 522 463 LYGY E TNN GGIYIE ETGTFFTYERTPEQSIYSLEELFR HEYTH FLQGRFEVPGLFGTGDM 522 463 LYGY E TNN GGIYIE ETGTFFTYERTPEOSIYSLEELFR HEYTH FLOGRFEVPGLFGTGDM 522 481 LYGY D TNN GGIYIE RDGTFFTYERTPEQSIYSLEDLFR HEMTH YLQGRYLIPELFGQGPI 540

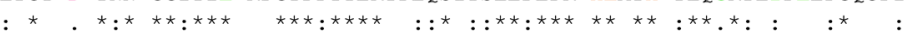

selectivity filter

545 YEKNRLTWFD E GTAEFFAGSTRTSGVLPRKSI $576 \ldots 595$ LNS GYDDSDWM FY 607 477 YDNDRLTWYE E GGAELFAGSTRTSGILPRKSI $508 \ldots 527$ VHS KYGAS-FE FY 538 523 YQNERLTWEQ E GNAEFFAGSTRTNNVVPRKSI $554 \ldots 572$ LFA KYGS--WD FY 582 526 YENERLSWEE E GNAEFFAGATRTDNVVPRKSI $557 \ldots 575$ LNA KYGT--WD FY 585 522 YONERLTWEQ E GNAEFFAGSTRTNNVVPRKSM $553 \ldots 571$ LFS KYGS--WD FY 581 523 YQNERLTWEQ E GNAEFFAGSTRTNNVVPRKSI $554 \ldots 572$ LFA KYGS--WD FY 582 523 YQNERLTWEQ E GNAEFFAGSTRTNNVVPRKSI $554 \ldots 572$ LFA KYGS--W- FY 582 523 YQNERLTWEQ E GNAEFFAGSTRTNDVVPRKSI $554 \ldots 572$ MFA KYGS--WD FY 582 523 YQNERLTWFQ E GNAEFFAGSTRTNDVVPRKSI $554 \ldots 572$ MFA TYGS--WD FY 582 541 YANERLTWFS E GGAEFFAGSTRTDRVVPRKTI $572 \ldots 590$ LYA TYGT--WD FY 600

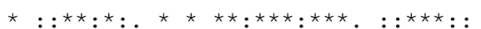

$\therefore: \quad$ : $\quad \star \star$

Figure 7. Comparison of catalytic centres of bacterial collagenases (a) Alignment of the catalytic centers of several clostridial and bacillial collagenases. ColG (Q9X721) and ColH (Q46085) from C. histolyticum, ColQ1 (B9J3S4) from B. cereus strain Q1, second collagenase (B9ITQ0) from B. cereus strain Q1, ColA (Q81BJ6) from B. cereus strain ATCC 14579, and one collagenase each from B. anthracis, B. mycoides, B. lonarensis, Lysinibacillus fusiformis and L. sphaericus (UniProt accession numbers indicated within figure). Structural annotations (edge strand in yellow, central helix in blue and gluzincin helix in light blue) are based on Eckhard et al. $^{15}$. The alignment was aided by Clustal Omega ${ }^{75}$. Calcium-binding residues, zinc-binding residues and the selectivity filter are shown in light green, orange and dark green, respectively. The zinc-stabilizing aspartate (in $\mathrm{ColH}$ ) and homologous residues in the other collagenases are highlighted in pink. (b) Close-up on the active sites of ColG (PDB: 4ARE), ColH (PDB: 4AR1) and the homology model of ColQ1. Modelling was performed using Modeller ${ }^{58}$. The upper half-domain, lower half-domain, calcium and zinc are shown in dark blue, light blue, light green and grey, respectively. Colours for the highlighted structural motifs and metal-binding residues are the same as in (a).

than that of ColG, yet in the structural homology model it more closely resembles the configuration found in ColG. It is however not identical to that of $\mathrm{ColH}$ but seems to be strongly conserved among the Bacillus and Lysinibacillus (putative) collagenases.

Given the dynamic nature of collagen substrate recognition and turnover by collagenases, it is interesting to analyse the thermally induced, metal-dependent unfolding of collagenases. The clostridial collagenases ColG and $\mathrm{ColH}$ both exhibited a monophasic unfolding behaviour, but differed strikingly in their metal dependence, cf. Fig. 3. The pronounced stabilization of ColG by the presence of zinc and calcium reflects its low metal affinity, whereas ColH was shown to have its catalytic zinc (and calcium) site always occupied ${ }^{16}$. The low zinc occupancy in ColG readily explains why it exhibits a low peptidolytic activity (Fig. 4).

ColQ1 shares with ColG a strong metal dependence in its thermal stability. However, contrasting both ColG and $\mathrm{ColH}$, the bacillial ColQ1 exhibited a pronounced biphasic unfolding, a behaviour characteristic for a two-domain protein. We questioned whether the two discrete unfolding events could be related to the activator domain and peptidase domain. Surprisingly, however, we found the isolated peptidase domain to account for the biphasic unfolding seen in the collagenase unit of ColQ1. The peptidase domain itself is segmented into an 


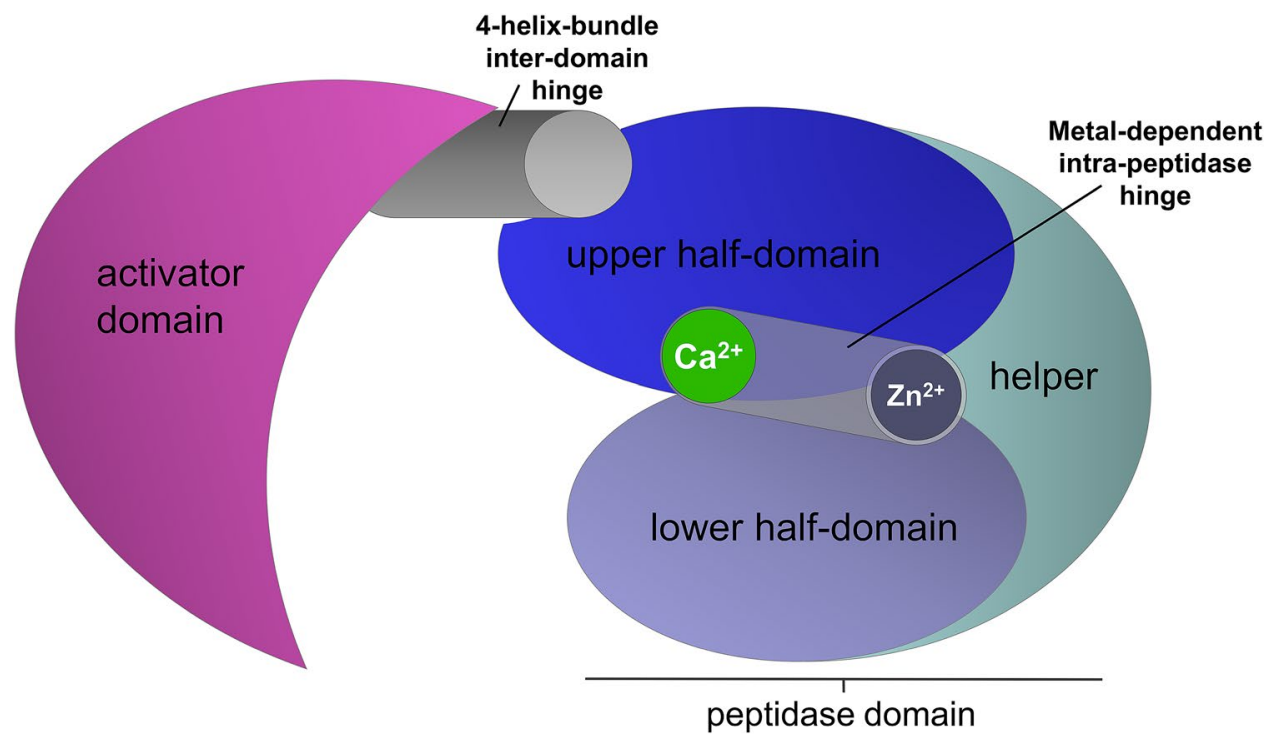

Figure 8. Schematic illustration of the hinge elements for collagenolytic, gelatinolytic and peptidolytic activities in bacterial collagenases.

upper and lower half-domain. At standard buffer conditions these two half-domains unfold separately, however upon addition of $10 \mu \mathrm{M} \mathrm{ZnCl}_{2}$ and $10 \mathrm{mM} \mathrm{CaCl}_{2}$ the unfolding of both domains is (1) stabilized and (2) coupled. Only a minor fraction unfolds prematurely, while the majority denatures cooperatively at $56.8^{\circ} \mathrm{C}$. The coupling of the (un-)folding of the lower and upper half-domains of the peptidase by $\mathrm{Ca}^{2+}$ and $\mathrm{Zn}^{2+}$ is consistent with their binding sites being placed at the interface of both half-domains, cf. Figure $7 \mathrm{~b}$. This metal-dependent hinge motion within the peptidase domain complements the functionally critical hinge between the activator domain and peptidase domain. The latter is formed by a four-helix bundle and is required for collagen degradation ${ }^{16}$. One way to interpret the strong collagenase activity in ColG and in particular in ColQ1 is that both the four-helix hinge and the metal hinge (Fig. 8) are required for efficient collagen recognition and processing. By contrast, the metal hinge appears much stiffer in $\mathrm{ColH}$, which may relate to its significantly reduced collagenolytic activity. It is also possible that the helper subdomain plays an as yet unclear role in regulating the opposing activities towards complex and simple peptide substrates.

Although ColQ1 originates from a $B$. cereus strain isolated from a deep-surface oil reservoir ${ }^{34}$, in which temperatures can rise on average by $3^{\circ} \mathrm{C}$ per $100 \mathrm{~m}$ in depth ${ }^{46}$ we found no pronounced thermophilicity in ColQ1 on the level of the collagenase unit. The highest melting temperature observed was $56.8^{\circ} \mathrm{C}$ for ColQ1 CU compared to $49.2^{\circ} \mathrm{C}$ and $53.5^{\circ} \mathrm{C}$ for $\mathrm{ColH} \mathrm{CU}$ and ColG CU in the presence of ions, respectively. This temperature fails to meet the thermal stability range of $80-100{ }^{\circ} \mathrm{C}$ for thermophilic proteins ${ }^{47}$. Yet the mesophilic nature of ColQ1 $\mathrm{CU}$ complies with its physiological function. There is no obvious rationale for the evolution of a thermophilic collagenase, as its physiological substrate collagen starts to unfold at $37^{\circ} \mathrm{C}^{48}$ and can then be degraded by various proteases (e.g. MM-1, $-2,-3,-9,-10^{48}$, cathepsin $B$ and $\mathrm{K}^{49}$, pepsin, $\operatorname{tryp} \sin ^{50}$ ).

While there are no reports that implicate bacillial collagenases as virulence factors in $B$. cereus-associated foodborne diseases, in case of $B$. cereus mediated endophthalmitis ${ }^{32}$ and periodontal diseases, however, collagenases have been found in the isolates of vitreous humor and dental plaques $32,33,51,52$. Considering the high collagenolytic efficiency of bacillial collagenases, as shown here for ColQ1 and for B. cereus ATCC 14579 ColA $^{28}$, we propose that these enzymes facilitate the infiltration of the target tissues by degradation of the protective surrounding extracellular matrix, which then allows the diffusion of other virulence factors into the tissue. Beecher et al. ${ }^{32}$, for example, observed a progressive degradation of the collagenous lens capsule prior to colonization of the lens cortex by B. cereus. The authors found a bacillial collagenase in the vitreous fluid of infected eyes, suggesting that it had breached the collagen barrier and thus enabled the entry of the bacteria. Yet, further research into the role of bacillial collagenases as virulence factor in this pathogenic settings is required.

In conclusion, we have shown here the recombinant expression and a comprehensive biophysical and enzymatic characterization of a novel collagenolytic enzyme from B. cereus strain Q1. We demonstrated that this collagenase (and potentially bacillial collagenases in general) have a remarkably high collagenolytic activity compared to the well-described clostridial collagenases. Since clostridial collagenases are already used in medical and biotechnological applications, such as the treatment of Dupuytren's contracture and in the food and leather industries $^{21,22,26,53}$, this highly active homologue could present an attractive improvement in these areas. Furthermore, we have shown for the first time that the rate-limiting step in bacterial collagenolysis is the unwinding of the triple helix, i.e. the helicase activity. 


\section{Methods}

Bioinformatic analysis. Signal peptide prediction was carried out using the SignalP 4.1 webserver ${ }^{39}$ and domain predictions were carried out using InterPro and $\mathrm{Pfam}^{54,55}$. Protein sequence alignments were performed with Blastp ${ }^{56}$ using the protein sequence of ColA from B. cereus strain Q1 (Uniprot accession B9J3S4) as the query and ColG (Q9X721), ColH (Q46085), ColT (Q899Y1) and ColA from B. cereus strain ATCC 14579 (Q81BJ6) as subject sequences. For alignment of the separate domains, domain boundaries of the three clostridial collagenases were taken from Eckhard et al., $2013^{15}$, while domain boundaries for ColQ1 and ColA were inferred from the abovementioned domain predictions and sequence homology to the clostridial collagenases (see Supplementary Table S1). Modelling of the ColQ1 structure was carried out using HHpred and Modeller ${ }^{57,58}$.

Cloning. The coding DNA sequences were amplified by polymerase chain reaction using synthesized plasmid DNA (E. coli codon-optimized full-length sequence of ColQ1 Eurofins Genomics, Ebersberg, Germany) as template and the appropriate primers (see Supplementary Table S2, Eurofins Genomics) containing the restriction enzyme sites BamHI and KpnI for cloning the insert into a modified pET15b vector containing an N-terminal $\mathrm{His}_{6}$-tag. The PCR products were purified using the GeneJET PCR Purification kit (Thermo Fisher Scientific, Waltham, USA). Vector and PCR products were digested with the appropriate restriction enzymes (FD BamHI/ KpnI, Thermo Fisher Scientific, Waltham, USA), purified via preparative DNA electrophoresis followed by gel extraction using the MinElute Gel Extraction Kit (Qiagen, Hilden, Germany), ligated and electrocompetent XL2blue cells (Stratagene, San Diego, USA) were transformed with the resulting plasmids following standard protocols. The E502A mutation was introduced via inverse $\mathrm{PCR}^{59}$. All constructs were verified by sequencing at Eurofins Genomics.

Recombinant protein expression and purification. ColG variants and $\mathrm{ColH}$ collagenase unit were expressed and purified as described previously ${ }^{40}$. Chemocompetent NiCo21(DE3) (New England Biolabs, Ipswich, USA) cells were transformed with E. coli codon-optimized plasmids encoding for the full-length mature and the collagenase unit of ColQ1 wild-type and catalytically dead mutants. Starter cultures were inoculated with a single clone from a fresh LB plate containing $100 \mu \mathrm{g} / \mathrm{ml}$ ampicillin and grown over night at $37^{\circ} \mathrm{C}$ and $230 \mathrm{rpm}$. Expression cultures were inoculated 1:500 with starter culture and grown at $37^{\circ} \mathrm{C}$ and $230 \mathrm{rpm}$ in baffled flasks. At $\mathrm{OD}_{600}$ of $0.3-0.4 \mathrm{NaCl}$ at a resulting concentration of $0.25 \mathrm{M}$ was added to promote accumulation of osmolytes and thereby enhance solubility of the recombinant protein ${ }^{60}$. Protein expression was induced in the early stationary phase $\left(\mathrm{OD}_{600} 1.0-1.2\right)$ by addition of $0.5 \mathrm{mM}$ IPTG; at the same time $1 \mathrm{mM} \mathrm{CaCl}_{2}$ was added. Protein was expressed over night at 17 or $25^{\circ} \mathrm{C}$ for the full-length enzyme and collagenase unit, respectively. The cells were collected by centrifugation at $4,000 \mathrm{~g}$ and $4{ }^{\circ} \mathrm{C}$ for $15 \mathrm{~min}$ and the periplasm was released by osmotic shock treatment ${ }^{61}$. Cells were resuspended in $50 \mathrm{mM} \mathrm{NaH}_{2} \mathrm{PO}_{4}, 300 \mathrm{mM} \mathrm{NaCl}, 10 \mathrm{mM}$ imidazole, $10 \mathrm{mM} \mathrm{MgCl}{ }_{2}$ pH 8.0 containing DNAseI (AppliChem, Darmstadt, Germany) and disrupted by sonication on ice $(5 \times 45 \mathrm{~s}$, $\approx 45 \mathrm{~W}$ ) using a Sonopuls HD 2070 ultrasound homogenizer (BANDELIN, Berlin, Germany). Insoluble components were removed by centrifugation at $16,000 \mathrm{~g}, 4^{\circ} \mathrm{C}$ for $2 \times 15 \mathrm{~min}$.

IMAC was carried out in batch columns containing pre-equilibrated Ni Sepharose 6 Fast Flow resin (GE Healthcare Life Sciences, Chicago, USA) using cooled buffers. Cleared supernatants were incubated on the column for $30 \mathrm{~min}$ at $4{ }^{\circ} \mathrm{C}$, the column was washed three times with 6 column volumes (CV) $50 \mathrm{mM} \mathrm{NaH}_{2} \mathrm{PO}_{4}$, $300 \mathrm{mM} \mathrm{NaCl}, \mathrm{pH} 8.0$ containing $25 \mathrm{mM}$ imidazole and the target protein was eluted with $9 \mathrm{CV}$ of the buffer above containing $250 \mathrm{mM}$ imidazole and $10 \mathrm{mM} \beta$-mercaptoethanol. The elution fractions were concentrated and rebuffered into $50 \mathrm{mM} \mathrm{NaH}_{2} \mathrm{PO}_{4}, 100 \mathrm{mM} \mathrm{NaCl}, 10 \mathrm{mM} \beta$-mercaptoethanol, < $10 \mathrm{mM}$ imidazole, $\mathrm{pH} 7.5$ by ultrafiltration. $\mathrm{N}$-terminal $\mathrm{His}_{6}$-tags were removed by tobacco etch virus (TEV) protease (produced in-house according to van den Berg et al. ${ }^{62}$ ) cleavage at $4{ }^{\circ} \mathrm{C}$ over night in a molar ratio of 1:5 (TEV-protease to target protein). To remove $\mathrm{TEV}$-protease (N-terminally $\mathrm{His}_{6}$-tagged) and uncleaved target protein, rechromatography on Ni Sepharose 6 Fast Flow was performed.

Size-exclusion chromatography was employed as a final polishing step at $22{ }^{\circ} \mathrm{C}$ using cooled buffer $(25 \mathrm{mM}$ HEPES, $100 \mathrm{mM} \mathrm{NaCl}, 5 \%$ glycerol, $1 \mathrm{mM}$ DTT, pH 7.5). Concentrated protein was separated on a Superdex S200 10/300 GL column (GE Healthcare Life Sciences, Chicago, USA) using the ÄKTA FPLC system and fractions found to be sufficiently pure by SDS-PAGE ( $\geq 90 \%)$ were flash frozen in liquid nitrogen and stored at $-80^{\circ} \mathrm{C}$.

Preparation of acetylated type I collagen from rat tails. All purification and chemical modification steps were carried out on ice or at $4{ }^{\circ} \mathrm{C}$. Type I collagen from rat tails was isolated as described by Steffensen et al. ${ }^{63}$. Collagen was lyophilized and stored at $-20^{\circ} \mathrm{C}$. Acetylation of collagen was adapted from Mookhtiar et al. ${ }^{64}$. In short, collagen was dialyzed against $10 \mathrm{mM}$ sodium borate, $0.2 \mathrm{M} \mathrm{CaCl}_{2}, \mathrm{pH} 9.0$, acetic anhydride was added to $1 \%(\mathrm{v} / \mathrm{v})$ over $1 \mathrm{~h}$ under gentle stirring, followed by another $30 \mathrm{~min}$ of stirring and dialysis into $0.1 \mathrm{M}$ acetic acid. Acetylated collagen was concentrated as high as possible by ultracentrifugation and dialyzed into enzyme reaction buffer. Collagen concentrations during this procedure were routinely monitored by a modified Lowry assay ${ }^{65}$ and the native fold of the substrate was verified by digestion with a-chymotrypsin ${ }^{66}$.

Thermal shift assay. Melting temperatures were determined in $20 \mathrm{mM}$ HEPES, $80 \mathrm{mM} \mathrm{NaCl}, \mathrm{pH} 7.5$, $5 \times$ SYPRO Orange dye (Molecular Probes, Eugene, USA). As indicated, $10 \mathrm{mM} \mathrm{CaCl}_{2}$ and $10 \mu \mathrm{M} \mathrm{ZnCl}_{2}, 10 \mathrm{mM}$ or $100 \mathrm{mM}$ EDTA were added. The temperature was raised in $1{ }^{\circ} \mathrm{C}$ increments from 25 to $95^{\circ} \mathrm{C}$ and fluorescence was recorded using the Applied Biosystems 7500 Real-Time PCR System (Thermo Fisher Scientific, Waltham, USA) at the SYBR Green setting. Data was analysed as described by Niesen et al. ${ }^{67}$ and Boltzmann fitting was performed with GraphPad Prism 5.0 (GraphPad Software, La Jolla, USA). 
Enzymatic assays. FALGPA. Peptidolytic activity was determined using FALGPA ${ }^{68}$. The assay was carried out in $100 \mathrm{mM}$ HEPES, $200 \mathrm{mM} \mathrm{NaCl}, 10 \mathrm{mM} \mathrm{CaCl}_{2}, 10 \mu \mathrm{M} \mathrm{ZnCl}_{2}, \mathrm{pH} 7.5$ at a final FALGPA (AppliChem PanReac, Darmstadt, Germany) concentration of $3.1 \mathrm{mM}$ at $25^{\circ} \mathrm{C}$. The substrate was dissolved in reaction buffer for $30 \mathrm{~min}$ and the concentration was verified by absorbance measurement at $305 \mathrm{~nm}\left(\varepsilon=24.7 \mathrm{mM}^{-1} \mathrm{~cm}^{-1}\right)$. Final enzyme concentrations were 25 and $50 \mathrm{nM}$ for ColH, 50 and $100 \mathrm{nM}$ for ColQ1 and between 0.5 and $5.1 \mu \mathrm{M}$ for ColG. Reaction progress was monitored via absorption measurement at $345 \mathrm{~nm}$ over $45 \mathrm{~min}$ in $30 \mathrm{~s}$ intervals in a Tecan Infinite M200 plate reader (Tecan, Grödig, Austria) and initial velocities were determined as described by Briers et al. ${ }^{69}$. All reactions were carried out at least in triplicate.

Gelatin zymography. The assay was carried out as described by Wilson et al. ${ }^{70}$ using $15 \mathrm{ng}$ collagenase per gel lane. Zymograms were developed in $50 \mathrm{mM}$ Tris- $\mathrm{HCl}, 200 \mathrm{mM} \mathrm{NaCl}, 0.02 \% \mathrm{Brij}_{35} \pm 5 \mathrm{mM} \mathrm{CaCl}_{2}, \pm 5 \mathrm{mM}$ EDTA, pH 7.5.

Fluorescein-labelled gelatin. DQ gelatin from pig skin from the EnzCheck Gelatinase/Collagenase Assay kit (Molecular Probes, Eugene, USA) was used as a substrate according to the manufacturer's instructions. The buffer was changed to $250 \mathrm{mM}$ HEPES, $150 \mathrm{mM} \mathrm{NaCl}, 5 \mathrm{mM} \mathrm{CaCl}_{2}, 5 \mu \mathrm{M} \mathrm{ZnCl}_{2}$, pH 7.5. E-64, PMSF, EDTA and 1,10-phenanthroline were added to final concentrations of $10 \mu \mathrm{M}, 1 \mathrm{mM}, 10 \mathrm{mM}$ and $10 \mathrm{mM}$, respectively. The reaction was carried out in $50 \mu \mathrm{l}$ total volume, $0.2 \mu \mathrm{g} / \mathrm{ml}$ final substrate concentration, $0.5-3 \mathrm{nM}$ final enzyme concentration and monitored in a Tecan Infinite M200 plate reader (Tecan, Grödig, Austria) for 8 min ( $5 \mathrm{~s}$ intervals). Initial velocities were determined as described by Briers et al. ${ }^{69}$. All reactions were carried out at least in triplicate.

Collagenolytic assay monitored via SDS-PAGE. Acid-soluble type I atelocollagen from bovine hides (Cell Guidance Systems, Cambridge, UK) at a final concentration of $1 \mathrm{mg} / \mathrm{ml}$ was digested at $25^{\circ} \mathrm{C}$ by $55 \mathrm{nM}$ collagenase in $250 \mathrm{mM}$ HEPES, $150 \mathrm{mM} \mathrm{NaCl}, 5 \mathrm{mM} \mathrm{CaCl}_{2}, 5 \mu \mathrm{M} \mathrm{ZnCl}_{2}, \mathrm{pH}$ 7.5. Samples were taken at indicated time points, the reaction was stopped by addition of $50 \mathrm{mM}$ EDTA and the degradation was visualised on 9\% SDS-PAGE gels. The correct fold of the collagen was verified by incubation with $0.83 \mu \mathrm{M} \alpha$-chymotrypsin (FLUKA, Buchs, Switzerland) over night.

Collagenolytic/gelatinolytic activity measurements monitored by fluorescamine labelling. Acetylated rat tail collagen (final concentration 3.83-0.02 $\mathrm{mg} / \mathrm{ml}$ ) was mixed with collagenase G and Q1 CU in concentrations ranging from 0.375 to $9 \mu \mathrm{M}$ and from 0.06 to $1.5 \mu \mathrm{M}$, respectively. The reaction was carried out in $100 \mathrm{mM}$ HEPES, $200 \mathrm{mM} \mathrm{NaCl}, 10 \mathrm{mM} \mathrm{CaCl}_{2}, 10 \mu \mathrm{M} \mathrm{ZnCl}_{2}, \mathrm{pH} 7.5$ at $25^{\circ} \mathrm{C}$. Samples were taken after 15, 45, 75, 105, 135 and $165 \mathrm{~s}$, immediately stopped with $83 \mathrm{mM}$ EDTA and put on ice. If necessary, samples were diluted to $<0.5 \mathrm{mg} / \mathrm{ml}$ collagen in reaction buffer containing $83 \mathrm{mM}$ EDTA and detection of primary amines (i.e.-after subtraction of background-new N-termini generated by proteolytic cleavage) was carried out by reaction with fluorescamine $\mathrm{e}^{71}$. All collagen concentrations were verified by picrosirius red assay ${ }^{72}$.

For gelatinolytic activity measurement acetylated rat tail collagen was denatured at $95^{\circ} \mathrm{C}$ for $10 \mathrm{~min}$, left to cool to $25^{\circ} \mathrm{C}$ and then diluted to the desired concentrations $(0.025-3 \mathrm{mg} / \mathrm{ml})$. To avoid (partial) refolding, gelatin stocks were either used immediately after denaturation or stored at $4{ }^{\circ} \mathrm{C}$ and denatured again, as described above, directly before use. Enzyme concentrations were between 15 and $50 \mathrm{nM}$ for ColG and between 10 and $100 \mathrm{nM}$ for ColQ1.

Enzyme concentrations were chosen to provide reaction velocities with $<10 \%$ substrate turnover in the measured time frame at a suitable signal-to-noise ratio. All reactions were carried out at least in triplicate. Reaction velocity was plotted against substrate concentration and $\mathrm{K}_{\mathrm{M}}$ and $\mathrm{V}_{\max }$ were determined by non-linear fitting with GraphPad Prism 5.0 (GraphPad Software, La Jolla, USA).

Received: 7 October 2020; Accepted: 4 February 2021

Published online: 18 February 2021

\section{References}

1. Mouw, J. K., Ou, G. \& Weaver, V. M. Extracellular matrix assembly: a multiscale deconstruction. Nat. Rev. Mol. Cell. Biol. 15, 771-785. https://doi.org/10.1038/nrm3902 (2014).

2. Kadler, K. Extracellular matrix. 1: fibgril-forming collagens. In Protein profile (ed. Sheterline, P.) 519-638 (Academic Press, London, 1994).

3. Olsen, B. R. \& Ninomiya, Y. Collagens. In Guidebook to the extracellular matrix, anchor, and adhesion proteins (eds Vale, T. \& Kreis, R.) 380-407 (Oxford University Press, Oxford, 1999).

4. Shoulders, M. D. \& Raines, R. T. Collagen structure and stability. Annu. Rev. Biochem. 78, 929-958. https://doi.org/10.1146/annur ev.biochem.77.032207.120833 (2009).

5. Nagase, H., Visse, R. \& Murphy, G. Structure and function of matrix metalloproteinases and TIMPs. Cardiovasc. Res. 69, 562-573. https://doi.org/10.1016/j.cardiores.2005.12.002 (2006).

6. Hatheway, C. L. Toxigenic clostridia. Clin. Microbiol. Rev. 3, 66-98 (1990).

7. Mookhtiar, K. A. \& Van Wart, H. E. Clostridium histolyticum collagenases: a new look at some old enzymes. Matrix Suppl. 1, 116-126 (1992).

8. Matsushita, O. et al. Gene duplication and multiplicity of collagenases in Clostridium histolyticum. J. Bacteriol. 181, 923-933 (1999).

9. Matsushita, O. \& Okabe, A. Clostridial hydrolytic enzymes degrading extracellular components. Toxicon 39, 1769-1780. https:// doi.org/10.1016/S0041-0101(01)00163-5 (2001).

10. Matsushita, O. et al. A study of the collagen-binding domain of a 116-kDa Clostridium histolyticum collagenase. J. Biol. Chem. 273, 3643-3648. https://doi.org/10.1074/jbc.273.6.3643 (1998). 
11. Wang, Y. K. et al. Mechanistic insight into the function of the C-terminal PKD domain of the collagenolytic serine protease deseasin MCP-01 from deep sea Pseudoalteromonas sp. SM9913: Binding of the PKD domain to collagen results in collagen swelling but does not unwind the collagen triple helix. J. Biol. Chem. 285, 14285-14291. https://doi.org/10.1074/jbc.M109.087023 (2010).

12. Bond, M. D. \& Van Wart, H. E. Characterization of the individual collagenases from Clostridium histolyticum. Biochemistry 23, 3085-3091. https://doi.org/10.1021/bi00308a036 (1984).

13. Bruggemann, H. et al. The genome sequence of Clostridium tetani, the causative agent of tetanus disease. Proc. Natl. Acad. Sci. U. S. A. 100, 1316-1321. https://doi.org/10.1073/pnas.0335853100 (2003).

14. Rawlings, N. D., Barrett, A. J. \& Bateman, A. MEROPS: the database of proteolytic enzymes, their substrates and inhibitors. Nucleic Acids Res. 40, D343-350. https://doi.org/10.1093/nar/gkr987 (2012).

15. Eckhard, U., Schonauer, E. \& Brandstetter, H. Structural basis for activity regulation and substrate preference of clostridial collagenases G, H, and T. J. Biol. Chem. 288, 20184-20194. https://doi.org/10.1074/jbc.M112.448548 (2013).

16. Eckhard, U., Schonauer, E., Nuss, D. \& Brandstetter, H. Structure of collagenase G reveals a chew-and-digest mechanism of bacterial collagenolysis. Nat. Struct. Mol. Biol. 18, 1109-1114. https://doi.org/10.1038/nsmb.2127 (2011).

17. Kuypers, M. M. M., Marchant, H. K. \& Kartal, B. The microbial nitrogen-cycling network. Nat. Rev. Microbiol. 16, 263-276. https ://doi.org/10.1038/nrmicro.2018.9 (2018).

18. Popoff, M. R. From saprophytic to toxigenic clostridia, a complex evolution based on multiple diverse genetic transfers and/or rearrangements. Res. Microbiol. 166, 221-224. https://doi.org/10.1016/j.resmic.2015.02.008 (2015).

19. Schönauer, E. et al. Discovery of a potent inhibitor class with high selectivity toward clostridial collagenases. J. Am. Chem. Soc. 139, 12696-12703. https://doi.org/10.1021/jacs.7b06935 (2017).

20. Shi, L. \& Carson, D. Collagenase Santyl ointment: a selective agent for wound debridement. J. Wound Ostomy Continence Nurs. 36, S12-16. https://doi.org/10.1097/WON.0b013e3181bfddla (2009).

21. Badalamente, M. A., Hurst, L. C., Benhaim, P. \& Cohen, B. M. Efficacy and safety of collagenase clostridium histolyticum in the treatment of proximal interphalangeal joints in dupuytren contracture: combined analysis of 4 phase 3 clinical trials. J. Hand. Surg. Am. 40, 975-983. https://doi.org/10.1016/j.jhsa.2015.02.018 (2015).

22. Rohit, A. et al. Prospective observation of Clostridium histolyticum collagenase for the treatment of Dupuytren's disease in 788 patients: the Austrian register. Arch. Orthop. Trauma Surg. https://doi.org/10.1007/s00402-019-03226-3 (2019).

23. Balamurugan, A. N. et al. A new enzyme mixture to increase the yield and transplant rate of autologous and allogeneic human islet products. Transplantation 93, 693-702. https://doi.org/10.1097/TP.0b013e318247281b (2012).

24. Hesse, F., Burtscher, H., Popp, F. \& Ambrosius, D. Recombinant enzymes for islet isolation: purification of a collagenase from Clostridium histolyticum and cloning/expression of the gene. Transplant. Proc. 27, 3287-3289 (1995).

25. Naftanel, M. A. \& Harlan, D. M. Pancreatic Islet transplantation. PLoS Med. 1, e58. https://doi.org/10.1371/journal.pmed.00100 58 (2004).

26. Allen Foegeding, E. \& Larick, D. K. Tenderization of beef with bacterial collagenase. Meat Sci. 18, 201-214. https://doi. org/10.1016/0309-1740(86)90034-3 (1986)

27. Thanikaivelan, P., Rao, J. R., Nair, B. U. \& Ramasami, T. Recent trends in leather making: processes, problems, and pathways. Crit. Rev. Environ. Sci. Technol. 35, 37-79. https://doi.org/10.1080/10643380590521436 (2005).

28. Abfalter, C. M. et al. Cloning, purification and characterization of the collagenase ColA expressed by Bacillus cereus ATCC 14579. PLoS ONE 11, e0162433. https://doi.org/10.1371/journal.pone.0162433 (2016).

29. Adiguzel, A. C., Bitlisli, B. O., Yasa, I. \& Eriksen, N. T. Sequential secretion of collagenolytic, elastolytic, and keratinolytic proteases in peptide-limited cultures of two Bacillus cereus strains isolated from wool. J. Appl. Microbiol. 107, 226-234. https://doi.org/10. 1111/j.1365-2672.2009.04200.x (2009).

30. Evans, D. G. \& Wardlaw, A. C. Gelatinase and collagenase production by certain species of Bacillus. J. Gen. Microbiol. 8, 481-487. https://doi.org/10.1099/00221287-8-3-481 (1953).

31. Peng, D. et al. A novel metalloproteinase virulence factor is involved in Bacillus thuringiensis pathogenesis in nematodes and insects. Environ. Microbiol. 18, 846-862. https://doi.org/10.1111/1462-2920.13069 (2016).

32. Beecher, D. J., Olsen, T. W., Somers, E. B. \& Wong, A. C. Evidence for contribution of tripartite hemolysin BL, phosphatidylcholinepreferring phospholipase C, and collagenase to virulence of Bacillus cereus endophthalmitis. Infect. Immun. 68, 5269-5276 (2000).

33. Makinen, K. K. \& Makinen, P. L. Purification and properties of an extracellular collagenolytic protease produced by the human oral bacterium Bacillus cereus (strain Soc 67). J. Biol. Chem. 262, 12488-12495 (1987).

34. Xiong, Z. et al. Complete genome sequence of the extremophilic Bacillus cereus strain Q1 with industrial applications. J. Bacteriol. 191, 1120-1121. https://doi.org/10.1128/JB.01629-08 (2009).

35. Madeira, F. et al. The EMBL-EBI search and sequence analysis tools APIs in 2019. Nucleic Acids Res. 47, W636-W641. https://doi. org/10.1093/nar/gkz268 (2019).

36. Barraud, P., Banerjee, S., Mohamed, W. I., Jantsch, M. F. \& Allain, F. H. A bimodular nuclear localization signal assembled via an extended double-stranded RNA-binding domain acts as an RNA-sensing signal for transportin 1. Proc. Natl. Acad. Sci. U. S. A. 111, E1852-1861. https://doi.org/10.1073/pnas.1323698111 (2014).

37. Finn, R. D. et al. Pfam: clans, web tools and services. Nucleic Acids Res. 34, D247-251. https://doi.org/10.1093/nar/gkj149 (2006).

38. Letunic, I. et al. SMART 5: domains in the context of genomes and networks. Nucleic Acids Res. 34, D257-260. https://doi. org/10.1093/nar/gkj079 (2006).

39. Petersen, T. N., Brunak, S., von Heijne, G. \& Nielsen, H. SignalP 4.0: discriminating signal peptides from transmembrane regions. Nat. Methods 8, 785-786. https://doi.org/10.1038/nmeth.1701 (2011).

40. Ducka, P. et al. A universal strategy for high-yield production of soluble and functional clostridial collagenases in E. coli. Appl. Microbiol. Biotechnol. 83, 1055-1065. https://doi.org/10.1007/s00253-009-1953-4 (2009).

41. Eckhard, U. et al. Biochemical characterization of the catalytic domains of three different clostridial collagenases. Biol. Chem. 390, 11-18. https://doi.org/10.1515/BC.2009.004 (2009).

42. Salvesen, G. S. \& Nagase, H. Inhibition of proteolytic enzymes. In Proteolytic enzymes: a practical approach (eds Beynon, R. \& Bond, J. S.) 105-130 (Oxford University Press, Oxford, 2001).

43. Harrington, D. J. Bacterial collagenases and collagen-degrading enzymes and their potential role in human disease. Infect. Immun. 64, 1885-1891 (1996).

44. Mallya, S. K., Mookhtiar, K. A. \& Van Wart, H. E. Kinetics of hydrolysis of type I, II, and III collagens by the class I and II Clostridium histolyticum collagenases. J. Protein Chem. 11, 99-107. https://doi.org/10.1007/bf01025096 (1992).

45. Ferreira, C. M. H., Pinto, I. S. S., Soares, E. V. \& Soares, H. M. V. M. (Un)suitability of the use of pH buffers in biological, biochemical and environmental studies and their interaction with metal ions: a review. RSC Adv. 5, 30989-31003. https://doi.org/10.1039/ C4RA15453C (2015).

46. Magot, M., Ollivier, B. \& Patel, B. K. Microbiology of petroleum reservoirs. Antonie Van Leeuwenhoek 77, 103-116. https://doi. org/10.1023/a:1002434330514 (2000).

47. Gromiha, M. M., Nagarajan, R. \& Selvaraj, S. Protein structural bioinformatics: an review. In Encyclopedia of bioinformatics and computational biology (eds Ranganathan, S. et al.) 445-459 (Academic Press, London, 2019).

48. Leikina, E., Mertts, M. V., Kuznetsova, N. \& Leikin, S. Type I collagen is thermally unstable at body temperature. Proc. Natl. Acad. Sci. U. S. A. 99, 1314-1318. https://doi.org/10.1073/pnas.032307099 (2002). 
49. Patel, S., Homaei, A., El-Seedi, H. R. \& Akhtar, N. Cathepsins: proteases that are vital for survival but can also be fatal. Biomed. Pharmacother. 105, 526-532. https://doi.org/10.1016/j.biopha.2018.05.148 (2018).

50. Northrop, J. H. Comparative hydrolysis of gelatin by pepsin, trypsin, acid, and alkali. J. Gen. Physiol. 4, 57-71. https://doi. org/10.1085/jgp.4.1.57 (1921).

51. Loesche, W. J., Paunio, K. U., Woolfolk, M. P. \& Hockett, R. N. Collagenolytic activity of dental plaque associated with periodontal pathology. Infect. Immun. 9, 329 (1974).

52. Söderling, E. \& Paunio, K. U. Conditions of production and properties of the collagenolytic enzymes by two Bacillus strains from dental plaque. J. Periodontal. Res. 16, 513-523 (1981).

53. Kanth, S. V., Venba, R., Madhan, B., Chandrababu, N. K. \& Sadulla, S. Studies on the influence of bacterial collagenase in leather dyeing. Dyes Pigments 76, 338-347. https://doi.org/10.1016/j.dyepig.2006.08.043 (2008).

54. El-Gebali, S. et al. The Pfam protein families database in 2019. Nucleic Acids Res. 47, D427-D432. https://doi.org/10.1093/nar/ gky995 (2018).

55. Mitchell, A. L. et al. InterPro in 2019: improving coverage, classification and access to protein sequence annotations. Nucleic Acids Res. 47, D351-d360. https://doi.org/10.1093/nar/gky1100 (2019).

56. Altschul, S. F., Gish, W., Miller, W., Myers, E. W. \& Lipman, D. J. Basic local alignment search tool. J. Mol. Biol. 215, 403-410. https ://doi.org/10.1016/s0022-2836(05)80360-2 (1990).

57. Zimmermann, L. et al. A completely reimplemented MPI bioinformatics toolkit with a new HHpred server at its core. J. Mol. Biol. 430, 2237-2243. https://doi.org/10.1016/j.jmb.2017.12.007 (2018).

58. Webb, B. \& Sali, A. Comparative protein structure modeling using MODELLER. Curr. Protoc. Protein Sci. 86, 2.9.1-2.9.37. https ://doi.org/10.1002/cpps.20 (2016).

59. Hemsley, A., Arnheim, N., Toney, M. D., Cortopassi, G. \& Galas, D. J. A simple method for site-directed mutagenesis using the polymerase chain reaction. Nucleic acids res. 17, 6545-6551. https://doi.org/10.1093/nar/17.16.6545 (1989).

60. de Marco, A., Vigh, L., Diamant, S. \& Goloubinoff, P. Native folding of aggregation-prone recombinant proteins in Escherichia coli by osmolytes, plasmid- or benzyl alcohol-overexpressed molecular chaperones. Cell Stress Chaperones 10, 329-339 (2005).

61. Quan, S., Hiniker, A., Collet, J. F. \& Bardwell, J. C. Isolation of bacteria envelope proteins. Methods Mol. Biol. 966, 359-366. https ://doi.org/10.1007/978-1-62703-245-2 22 (2013).

62. van den Berg, S., Löfdahl, P. - А̊., Härd, T. \& Berglund, H. Improved solubility of TEV protease by directed evolution. J. Biotechnol. 121, 291-298. https://doi.org/10.1016/j.jbiotec.2005.08.006 (2006).

63. Steffensen, B., Wallon, U. M. \& Overall, C. M. Extracellular matrix binding properties of recombinant fibronectin type II-like modules of human $72-\mathrm{kDa}$ gelatinase/type IV collagenase. High affinity binding to native type I collagen but not native type IV collagen. J. Biol. Chem. 270, 11555-11566 (1995).

64. Mookhtiar, K. A., Mallya, S. K. \& Van Wart, H. E. Properties of radiolabeled type I, II, and III collagens related to their use as substrates in collagenase assays. Anal. Biochem. 158, 322-333. https://doi.org/10.1016/0003-2697(86)90557-9 (1986).

65. Komsa-Penkova, R., Spirova, R. \& Bechev, B. Modification of Lowry's method for collagen concentration measurement. J. Biochem. Biophys. Methods 32, 33-43 (1996).

66. Bruckner, P. \& Prockop, D. J. Proteolytic enzymes as probes for the triple-helical conformation of procollagen. Anal. Biochem. 110, 360-368. https://doi.org/10.1016/0003-2697(81)90204-9 (1981).

67. Niesen, F. H., Berglund, H. \& Vedadi, M. The use of differential scanning fluorimetry to detect ligand interactions that promote protein stability. Nat. Protoc. 2, 2212-2221. https://doi.org/10.1038/nprot.2007.321 (2007).

68. Van Wart, H. E. \& Steinbrink, D. R. A continuous spectrophotometric assay for Clostridium histolyticum collagenase. Anal. Biochem. 113, 356-365. https://doi.org/10.1016/0003-2697(81)90089-0 (1981).

69. Briers, Y., Lavigne, R., Volckaert, G. \& Hertveldt, K. A standardized approach for accurate quantification of murein hydrolase activity in high-throughput assays. J. Biochem. Biophys. Methods 70, 531-533. https://doi.org/10.1016/j.jbbm.2006.10.009 (2007).

70. Wilson, M. J., Strasser, M., Vogel, M. M. \& Sinha, A. A. Calcium-dependent and calcium-independent gelatinolytic proteinase activities of the rat ventral prostate and its secretion: characterization and effect of castration and testosterone treatment. Biol. Reprod. 44, 776-785 (1991).

71. Bantan-Polak, T., Kassai, M. \& Grant, K. B. A comparison of fluorescamine and naphthalene-2,3-dicarboxaldehyde fluorogenic reagents for microplate-based detection of amino acids. Anal. Biochem. 297, 128-136. https://doi.org/10.1006/abio.2001.5338 (2001).

72. Marotta, M. \& Martino, G. Sensitive spectrophotometric method for the quantitative estimation of collagen. Anal. Biochem. 150, 86-90. https://doi.org/10.1016/0003-2697(85)90443-9 (1985).

73. Bauer, R. et al. Structures of three polycystic kidney disease-like domains from Clostridium histolyticum collagenases ColG and ColH. Acta Crystallogr. D Biol. Crystallogr. 71, 565-577. https://doi.org/10.1107/s1399004714027722 (2015).

74. Bauer, R. et al. Structural comparison of ColH and ColG collagen-binding domains from clostridium histolyticum. J. Bacteriol. 195, 318-327. https://doi.org/10.1128/JB.00010-12 (2013).

75. McWilliam, H. et al. Analysis tool web services from the EMBL-EBI. Nucleic Acids Res. 41, W597-W600. https://doi.org/10.1093/ nar/gkt376 (2013).

\section{Acknowledgements}

We thankfully acknowledge financial support by the Austrian Science Fund (FWF P 31843, W 01213) and by the Austrian Federal Ministry of Science, Research, and Economy. We are very grateful to Christopher Overall for technical expertise on collagen extraction. We thank Martina Wiesbauer for excellent technical support and Peter Hammerl for provision of rat tails.

\section{Author contributions}

E.S. and H.B. designed the research; I.J.H. performed the experiments and analysed the data; E.S. and H.B. helped with data analysis and interpretation; I.J.H. and H.B. wrote the manuscript; I.J.H. prepared the figures; all authors reviewed the manuscript.

\section{Competing interests}

The authors declare no competing interests.

\section{Additional information}

Supplementary Information The online version contains supplementary material available at https://doi. org/10.1038/s41598-021-83744-6.

Correspondence and requests for materials should be addressed to H.B. or E.S. 
Reprints and permissions information is available at www.nature.com/reprints.

Publisher's note Springer Nature remains neutral with regard to jurisdictional claims in published maps and institutional affiliations.

(c) (i) Open Access This article is licensed under a Creative Commons Attribution 4.0 International License, which permits use, sharing, adaptation, distribution and reproduction in any medium or format, as long as you give appropriate credit to the original author(s) and the source, provide a link to the Creative Commons licence, and indicate if changes were made. The images or other third party material in this article are included in the article's Creative Commons licence, unless indicated otherwise in a credit line to the material. If material is not included in the article's Creative Commons licence and your intended use is not permitted by statutory regulation or exceeds the permitted use, you will need to obtain permission directly from the copyright holder. To view a copy of this licence, visit http://creativecommons.org/licenses/by/4.0/.

(C) The Author(s) 2021 